\title{
Al-Based Nano-Sized Composite Energetic Materials (Nano-CEMs): Preparation, Characterization, and Performance
}

\author{
Weiqiang Pang ${ }^{1,2, *}$, Xuezhong Fan ${ }^{1}$, Ke Wang ${ }^{1}$, Yimin Chao ${ }^{3}{ }^{-}$, Huixiang $\mathrm{Xu}^{1,2}$, Zhao Qin ${ }^{2}$ \\ and Fengqi Zhao ${ }^{2}$ \\ 1 The Third Department, Xi'an Modern Chemistry Research Institute, Xi'an 710065, China; \\ xuezhongfan@126.com (X.F.); zhuzhangmangxiewk@163.com (K.W.); xhx204@163.com (H.X.) \\ 2 Science and Technology on Combustion and Explosion Laboratory, Xi'an Modern Chemistry \\ Research Institute, Xi'an 710065, China; qzhao087@hotmail.com (Z.Q.); zhaofqi@163.com (F.Z.) \\ 3 School of Chemistry, University of East Anglia, Norwich Research Park, Norwich NR4 7TJ, UK; \\ y.chao@uea.ac.uk \\ * Correspondence: nwpu_pwq@163.com; Tel.: +86-029-88291063
}

Received: 21 April 2020; Accepted: 25 May 2020; Published: 29 May 2020

\begin{abstract}
As one of the new types of functional materials, nano-sized composite energetic materials (nano-CEMs) possess many advantages and broad application prospects in the research field of explosives and propellants. The recent progress in the preparation and performance characterization of Al-based nano-CEMs has been reviewed. The preparation methods and properties of Al-based nano-CEMs are emphatically analyzed. Special emphasis is focused on the improved performances of Al-based nano-CEMs, which are different from those of conventional micro-sized composite energetic materials (micro-CEMs), such as thermal decomposition and hazardous properties. The existing problems and challenges for the future work on Al-based nano-CEMs are discussed.
\end{abstract}

Keywords: composite energetic materials; nano-sized particles; Al-based; morphology performance; thermal decomposition; hazardous properties

\section{Introduction}

Nano-sized composite energetic materials (nano-CEMs), owing to their large specific surface area, high surface energy, and high surface activity, can realize the nanometer of energetic materials in the process of preparation, storage, and application [1,2]. Moreover, nano-CEMs can integrate the characteristics of each component, thus the new types of energetic materials with various characteristics can be obtained, which can reduce the size of reactants in composites to nano-scale, and then increase the contact interfacial area effectively between materials, so as to solve the problem of slow transmission speed of micro-sized composite energetic materials (micro-CEMs) owing to large particles (chemical reaction rate, mass transfer, and heat transfer), and obtain energetic materials with energy density and a high energy release rate [3,4]. In addition, the energy density of nano-sized energetic composites prepared by the sol-gel method is two times the monomolecular energetic material [5]. The mass transfer speed between the oxidant and the aluminum powder in the pore is fast and the reaction is sensitive. The burning speed is more than 1000 times compared with that of the similar ordinary oxides. Therefore, nano-CEMs as a new type of energetic material have attracted wide interests in the research community. $\mathrm{Al}$ is widely used to increase the energy and raise the flame temperature in rocket propellants because of its high combustion enthalpy, easy availability, low toxicity, and good stability in energetic applications, such as propellants, pyrotechnics, and explosives. Especially, nano-sized Al $(\mathrm{nAl})$ is broadly exploited to improve performance incrementing the burning rate and combustion 
efficiency of energetic systems, leading to shorter ignition delays and shorter agglomerate burning times with respect to propellants containing $\mu \mathrm{Al}$ [6-9]. In this paper, the developments and achievements in the preparation and performance of Al-based nano-CEMs are reviewed. The preparation methods and properties of Al-based nano-CEMs are emphatically analyzed, and the existing problems and challenges in the future work are reviewed.

\section{Preparation Methods of Nano-CEMs}

Nano-CEMs, being composed of one or more principal energetic components and some additives or binders, have been widely used in military. The uniform dispersing of energetic materials with nano-sized components can display the surface activities, improving the performance of traditional energetic materials and enhancing their practical applications. There are many methods to prepare the nano-CEMs, such as the solid phase method, liquid phase method, and gas phase method (according to the state of raw materials), as well as physical and chemical methods (according to the prepared techniques) $[1,5,10]$; while there is a big difference for the preparation methods of nano-CEMs mentioned above, here, the mail methods on their preparation were reviewed.

In the last two decades, nano-sized metal matrix composites have witnessed tremendous growth, and particulate-reinforced nanocomposites have been extensively employed in the propulsion field for their tremendous advantages. As we know, non-homogeneous particle dispersion and poor interface bonding are the main drawbacks of conventional manufacturing techniques. A critical review of nanocomposite manufacturing processes is presented; the distinction between ex situ and in situ processes is discussed in some detail. Moreover, in situ gas/liquid processes are elaborated and their advantages are discussed [11]. It provides the reader with an overview of nanocomposite manufacturing methods along with a clear understanding of advantages and disadvantages.

\subsection{Sol-Gel Method}

The sol-gel method is one of the most important preparation methods for nano-CEMs, so the preparation of Al-based nano-CEMs will focus on this method. On the one hand, this method can control the components accurately, and provide the feasibility for obtaining the nano-sized materials with controllable and uniform density; one the other hand, it allows the components to mix directly at the nano-scale.

The method is mainly used to prepare the metal oxide-based nano-CEMs. In order to make the oxidant or fuel into sol, other components are added to form gel. After the gel was formed, the porous aerogels with low density could be obtained by supercritical fluid extraction, and the xerogels with high density could be obtained under slow evaporation and at a certain pressure. Then, the sol-gel forms the main framework, and fuel and the other components are filled in it. The metal oxide sol can be obtained using hydrolyze metal salts and alkoxy metals. Figure 1 shows the typical process for sol-gel method preparation.

$$
\begin{gathered}
\mathrm{M}_{\mathrm{a}} \mathrm{X}_{\mathrm{b}}+\mathrm{bH}_{2} \mathrm{O} \rightarrow \mathrm{M}_{\mathrm{a}}\left(\mathrm{H}_{2} \mathrm{O}\right)_{\mathrm{b}}+\mathrm{bX} \\
\mathrm{M}_{\mathrm{a}}\left(\mathrm{H}_{2} \mathrm{O}\right)_{\mathrm{b}}+2 \mathrm{~b} \text { [proton scavnger] } \rightarrow \mathrm{M}_{\mathrm{a}} \mathrm{O}_{\mathrm{b}}+2 \mathrm{~b} \text { [proton scavenger-H] } \\
\mathrm{M}_{\mathrm{a}}(\mathrm{OR})_{\mathrm{b}}+5 \mathrm{H}_{2} \mathrm{O} \rightarrow \mathrm{Ma}(\mathrm{OH})_{b}+\mathrm{bROH} \\
\mathrm{M}_{\mathrm{a}}(\mathrm{OH})_{\mathrm{b}} \rightarrow \mathrm{M}_{\mathrm{a}} \mathrm{O}_{1 / 2 \mathrm{~b}}+1 / 2 \mathrm{bH}_{2} \mathrm{O}
\end{gathered}
$$

Nano-sized composite energetic materials of $\mathrm{Al} / \mathrm{Fe}_{2} \mathrm{O}_{3}, \mathrm{RDX}$ (hexogen, cyclotrimethylenetrinitramine)/ $\mathrm{RF}$ (resorcinol-formaldehyde), and $\mathrm{RDX} / \mathrm{SiO}_{2}$ were prepared by this method [13-15]. Compared with the nano-sized composite particles by means of the mechanical mill method, the thermal decomposition temperature can be forwarded by addition of nano-sized RDX/RF composite energetic materials by the sol-gel method; the mechanical sensitivity reduced as well, indicating that it has great potential application in micro initiating explosive devices. 


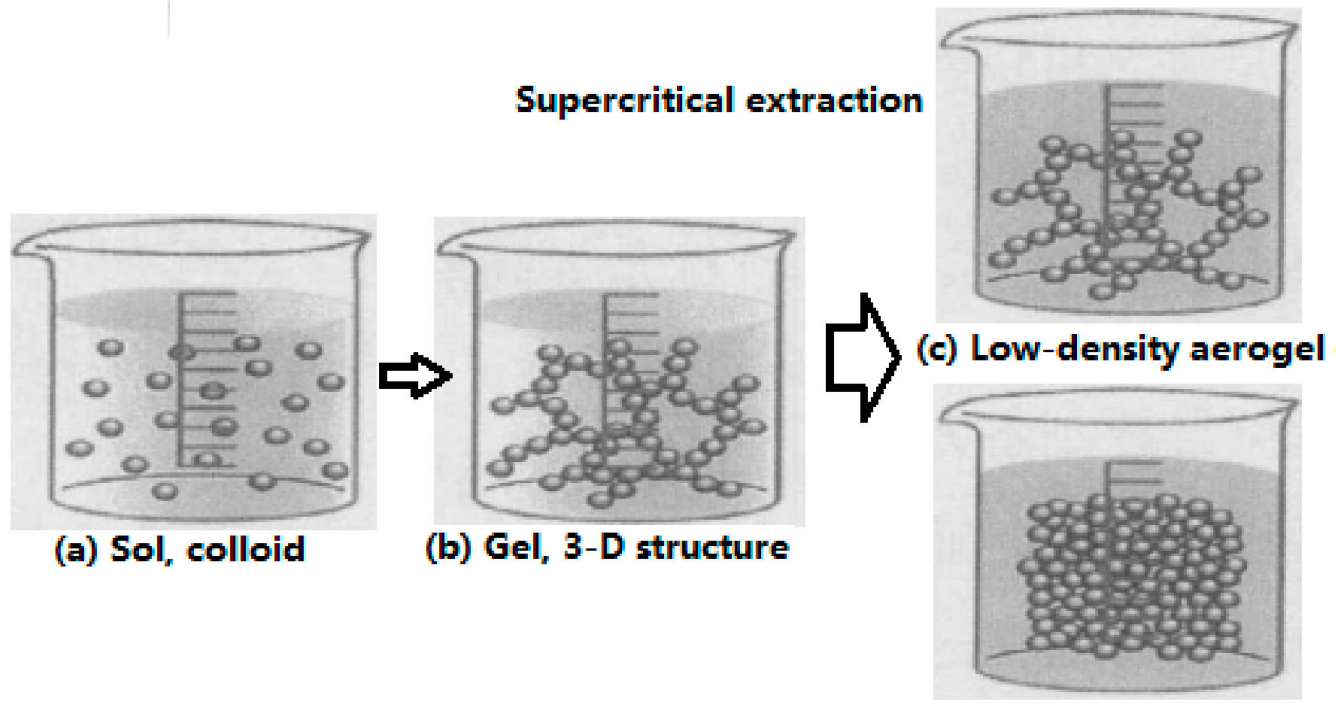

(d) High-density xerogel

Figure 1. Typical process for sol-gel method preparation. (a) Sol, colloid; (b) Gel, 3D structure; (c) Low-density aerogel; (d) High-density xerogel. Reproduced from [12], with permission from Elsevier, 2001.

\subsection{Solvent/Nonsolvent Method}

The solvent/nonsolvent method for nano-CEMs' preparation is based on crystallography. Nanosized cuprous dichromate particles coated with perchlorate crystal were prepared, and the particle size can be effectively controlled by adjusting the mass ratio of solvent to nonsolvent. The catalytic effect of nano-CEMs prepared by this method on ammonium perchlorate can be greatly improved, and the thermal decomposition reaction temperature with ammonium perchlorate was obviously decreased, thus the intensity of the thermal decomposition reaction was enhanced [16]. Nano-sized Al/AP (ammonium perchlorate) composite energetic materials were prepared with the solvent/nonsolvent method, the second thermal decomposition temperature decreased after addition of prepared nano particles, while the total heat release increased [17]. Nano-sized AP/CC (copper chromite) and $\mathrm{AP} / \mathrm{Fe}_{2} \mathrm{O}_{3}$ composite energetic materials were also prepared by the same method, which has good efficacy [18].

\subsection{High-Energy Ball Milling Method}

The high-energy ball milling method, which makes the hard ball impact, grind, and stir the raw material intensively according to the rotation and vibration actions, and makes it into nano-sized particles. Nano-sized $\mathrm{Al} / \mathrm{B} / \mathrm{Fe}_{2} \mathrm{O}_{3}, \mathrm{AP} / \mathrm{CuO}, \mathrm{AP} / \mathrm{CC}$ (copper chromite), and $\mathrm{Al} / \mathrm{RDX}$ composite energetic materials were prepared by this method $[19,20]$. The formation of nano-sized AP/CC composite particles can increase the contact area between ammonium perchlorate and copper dichromate, improving the dispersion and uniformity of the prepared particles, thus enhancing the catalysis effect of copper dichromate and reducing the thermal decomposition temperature of AP (For nano-sized $\mathrm{Al} / \mathrm{B} / \mathrm{Fe}_{2} \mathrm{O}_{3}$ composition, see Section 3.2.1).

\subsection{Spray Drying Method}

The spray drying method is the process of atomizing small particles and drying them with solution, suspension, emulsion, sol, and so on. It is the main process for preparing submicron and nano-sized particles in industry, and its equipment is simple, low cost, and highly efficient. HMX-(octogen, cyclotetramethylenetetranitramine), RDX-, and CL-20 (hexanitrohexaazaisowurtzitane)-based nano-sized composite energetic materials were prepared by means of the spray drying method, and the process was optimized [21]. Compared with the original particles, the average particle size of prepared HMX-based composite is $30-100 \mathrm{~nm}$, the activation energy and thermal sensitivity are much 
lower than that of pure HMX, and the impact sensitivity of sample with NC (nitrocellulose) as the binder has little change. For the RDX-based nano-sized composite, the addition of different binders can greatly reduce the impact sensitivity of RDX. For example, with $\mathrm{F}_{2602}$ as the binder, the activation energy of nano-sized CL-20/ $\mathrm{F}_{2602}$ composite increased, the impact sensitivity decreased significantly, while the thermal sensitivity had little change.

\subsection{Other Methods}

Hydrothermal reactions have been widely recognized in natural and artificial systems. Particularly, the formation, production, alteration, and decomposition of all substances and materials in natural systems are always related to the action of water (aqueous solutions) at higher temperatures under different pressures. Hydrothermal/solvothermal is another significant and proposed method to prepare nano-sized energetic materials. The feature and future of hydrothermal/solvothermal reactions for synthesis/preparation of nano-materials with desired shapes, sizes, and structures were elaborated [22].

The nano-sized $\mathrm{Al} / \mathrm{Al}_{2} \mathrm{O}_{3}(\mathrm{p})$ composites were fabricated from $\mathrm{Al}-\mathrm{K}_{2} \mathrm{ZrF}_{6}-\mathrm{Na}_{2} \mathrm{~B}_{4} \mathrm{O}_{7}$ system by sonochemistry in situ reaction. The fabrication mechanisms, including high intensity ultrasonic influence on microstructures and reinforcement particles-aluminum matrix interface, were investigated by X-ray diffraction (XRD), scanning electron microscopy (SEM), and transmission electron microscopy (TEM), and the reaction mechanisms were investigated [23]. The results show that the component of the as-prepared composites is $\mathrm{Al}_{2} \mathrm{O}_{3}$ reinforcement. $\mathrm{Al}_{2} \mathrm{O}_{3}$ particles are uniformly distributed in the aluminum matrix, the morphologies of $\mathrm{Al}_{2} \mathrm{O}_{3}$ particles present in a nearly sphere-shape, the sizes are in the range of $20-100 \mathrm{~nm}$, and the interfaces are net and no interfacial outgrowth is observed. The sonochemistry method was reviewed for use in the fabrication of nanomaterials [24].

Freeze-drying is another one of the effective methods to prepare the nano-sized composites. Al/AP nano-sized composites containing nano-sized aluminum powder with low density were prepared by means of the freeze-drying process $[25,26]$; this method has been used in solid rocket propellants. The reduction method, EEW (electro-exploding wire), CVD (chemical vapor deposition), and PCD (photo catalytic degradation) are well known methods to prepare nano-sized energetic materials. Different from the traditional mixture of reductant and oxidant, the porous metal matrix composite has nano-sized holes and an extremely high specific surface area, and the contact area between oxidant and reductant is large, which displays different performances of explosion characteristics [27-30].

\section{Characteristics and Performance of Nano-CEMs}

\subsection{Al-Based Binary System}

\subsubsection{Nano-Sized $\mathrm{Al} / \mathrm{Fe}_{2} \mathrm{O}_{3}$ Energetic Composite}

Nano-sized $\mathrm{Al}(\mathrm{s}) / \mathrm{Fe}_{2} \mathrm{O}_{3}$ composites are readily produced from a solution of $\mathrm{Fe}(\mathrm{III})$ salt by adding an organic epoxide and metal powder, and nano-CEMs formed with $\mathrm{Fe}_{2} \mathrm{O}_{3}$ as metal oxide and $\mathrm{Al}$ as fuel, that is, super thermite, have an extremely fast chemical reaction and the burning rate can reach up to 1000 times that of ordinary thermite, which can thus generate an extremely fast reaction wave and release huge energies $[4,10,12]$. Nano-sized $\mathrm{Al} / \mathrm{Fe}_{2} \mathrm{O}_{3}$ composites were prepared by Gash et al., and the gel structure was observed by high resolution transmission electron microscopy (HRTEM) [21]. It was found that the nano-sized $\mathrm{Al} / \mathrm{Fe}_{2} \mathrm{O}_{3}$ energetic composites were composed of 3-10 nm Fe ${ }_{2} \mathrm{O}_{3}$ clusters that are in intimate contact with ultrafine $\mathrm{Al}$ particles with $25 \mathrm{~nm}$ in diameter, and the $\mathrm{Al}$ particles have an oxide coating with thickness of $\sim 5 \mathrm{~nm}$. This value agrees well with the pristine ultrafine grain $\mathrm{Al}$ powder, indicating that the sol-gel synthetic method and processing does not significantly perturb the metal fuel. Nonetheless, both qualitative and quantitative characterizations have shown that these materials are indeed energetics, while the materials described here are relatively insensitive to standard impact, electrostatic spark, and friction tests. Qualitatively, it does appear that these nano-sized 
energetic composites burn faster, which are more sensitive to thermal ignition than their conventional counterparts, and the aerogel materials are more sensitive to ignition than those of xerogels.

Nano-sized $\mathrm{Al} / \mathrm{Fe}_{2} \mathrm{O}_{3}$ energetic composite was prepared by means of the sol-gel method as well as with the supercritical fluid drying method in China [26,27,31,32]; SEM photographs are listed in Figure 2. The experimental results showed the structure of nano-sized $\mathrm{Al} / \mathrm{Fe}_{2} \mathrm{O}_{3}$ composite energetic material was a significant fiber network. The average particle size of $\mathrm{Al}$ in the $\mathrm{Al} / \mathrm{Fe}_{2} \mathrm{O}_{3}$ composite was $40 \mathrm{~nm}$. The specific surface area of the $\mathrm{Al} / \mathrm{Fe}_{2} \mathrm{O}_{3}$ composite was $147.9 \mathrm{~m}^{2} / \mathrm{g}$, which is much smaller than that of blank $\mathrm{Fe}_{2} \mathrm{O}_{3}$ aerogel. Its average pore size was $8 \mathrm{~nm}$ and the distribution of pore size was more uniform. From the results, it was believed that the sol-gel method can provide processing advantages over the conventional methods in the areas of cost, purity, homogeneity, and safety at the very least, and potentially act as energetic materials with interesting and special properties.
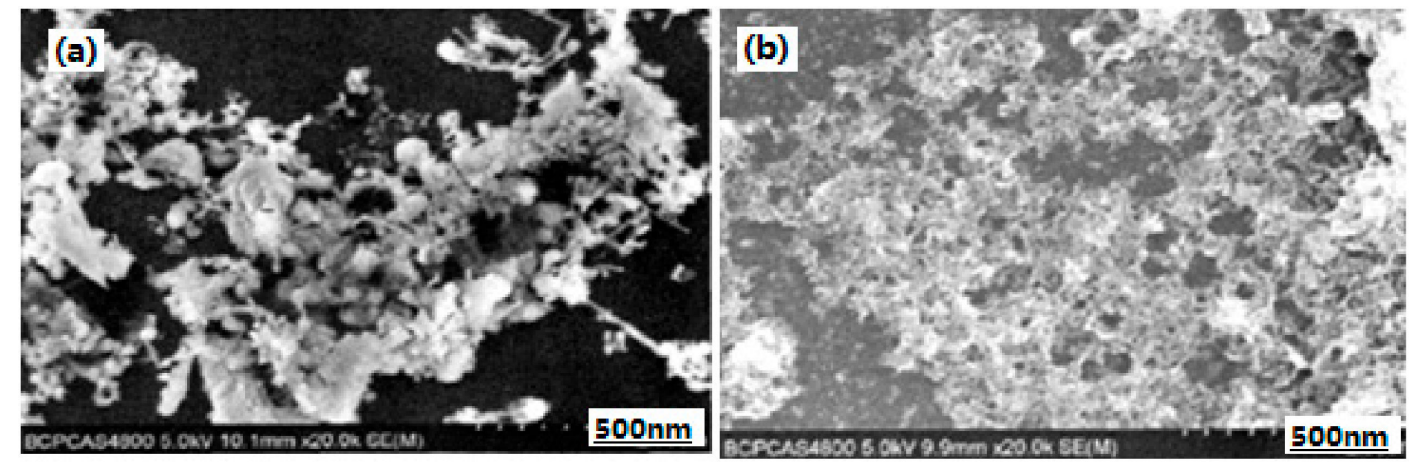

Figure 2. Scanning electron microscopy (SEM) photographs of $\mathrm{Fe}_{2} \mathrm{O}_{3}$ aerogel (a) and $\mathrm{Al} / \mathrm{Fe}_{2} \mathrm{O}_{3}$ composite energetic material (b). Reproduced from [31], with permission from Huo Zha Yao Xue Bao, 2010.

\subsubsection{Nano-Sized Al/NC Energetic Composite}

In order to utilize the full potentials of the existing energetic materials, nano-sized $\mathrm{Al} /$ nitrocellulose $(\mathrm{Al} / \mathrm{NC})$ composite materials were prepared with the mass ratio of $\mathrm{nAl}$ to $\mathrm{NC}$ of $0: 10,1: 10,3: 10,5: 10$, 7:10, and 9:10, respectively, through the sol-gel and supercritical $\mathrm{CO}_{2}$ drying methods. The structures of nano-CEMs were characterized by SEM and DSC methods. The physical mixed Al/NC and NC aerogel/Al mixture with the same mass ratio as that of nano-sized $\mathrm{Al} / \mathrm{NC}$ composites was prepared as the compared composition at the same time. SEM images of different composite samples are shown in Figure 3. Al elements distribution in nano-sized Al/NC energetic composite by EDS (energy dispersive spectroscopy) analysis are shown in Figure 4. The experimental results show that the nano-sized $\mathrm{Al} / \mathrm{NC}$ composite materials belong to mesoporous material and $\mathrm{nAl}$ powder is well-distributed in the gel matrix. The specific surface area of the $\mathrm{Al} / \mathrm{NC}$ particle decreases with the increasing $\mathrm{Al}$ powder mass fraction. When the mass ratio of $\mathrm{Al} / \mathrm{NC}$ is $5: 10$, the decomposition heat per unit mass of $\mathrm{NC}$ increases from $1689.21 \mathrm{~J} \cdot \mathrm{g}^{-1}$ to $2408.07 \mathrm{~J} \cdot \mathrm{g}^{-1}$.

\subsubsection{Nano-Sized $\mathrm{Al} / \mathrm{MnO}_{2}$ Energetic Composite}

Owing to the close contact area and uniform distribution between metal fuel and oxidant, nano-structured energetic materials have better energy release performance and ignition performance. Nano-structured energetic composite composed of $\mathrm{MnO}_{2}$ nano sheets with root-embedded $\mathrm{Al}$ on silicon wafer was prepared [34]. Figure 5 shows the SEM photos of $\mathrm{MnO}_{2}$ and nano-sized $\mathrm{Al} / \mathrm{MnO}_{2}$ composite particles. As shown, the thickness of $\mathrm{MnO}_{2}$ grown on the silicon substrate is $900 \mathrm{~nm}$, and the thickness of each sheet is less than $10 \mathrm{~nm}$. The uniform distribution of $\mathrm{MnO}_{2}$ nano-flakes on the whole silicon substrate indicates that this method can realize the growth of $\mathrm{MnO}_{2}$ on the silicon wafer with a large surface area (Figure $5 \mathrm{a}, \mathrm{c}$ ). Moreover, $\mathrm{Al}$ can deposit on the porous $\mathrm{MnO}_{2}$ nano sheet successfully, and there was some $\mathrm{Al}$ powder at the interface of $\mathrm{Si}-\mathrm{MnO}_{2}$, indicating that $\mathrm{Al}$ could fill in the porous 
structure of $\mathrm{MnO}_{2}$ nano sheet and come into close contact with the $\mathrm{MnO}_{2}$ nano sheet (Figure 5b). Additionally, the deposited $\mathrm{Al}$ is "rooted" in the porous $\mathrm{MnO}_{2}$ and "grows" into a rod-shaped structure, while the surplus rod-shaped Al aggregates and forms a densed vertical "coral" structure (Figure 5d).
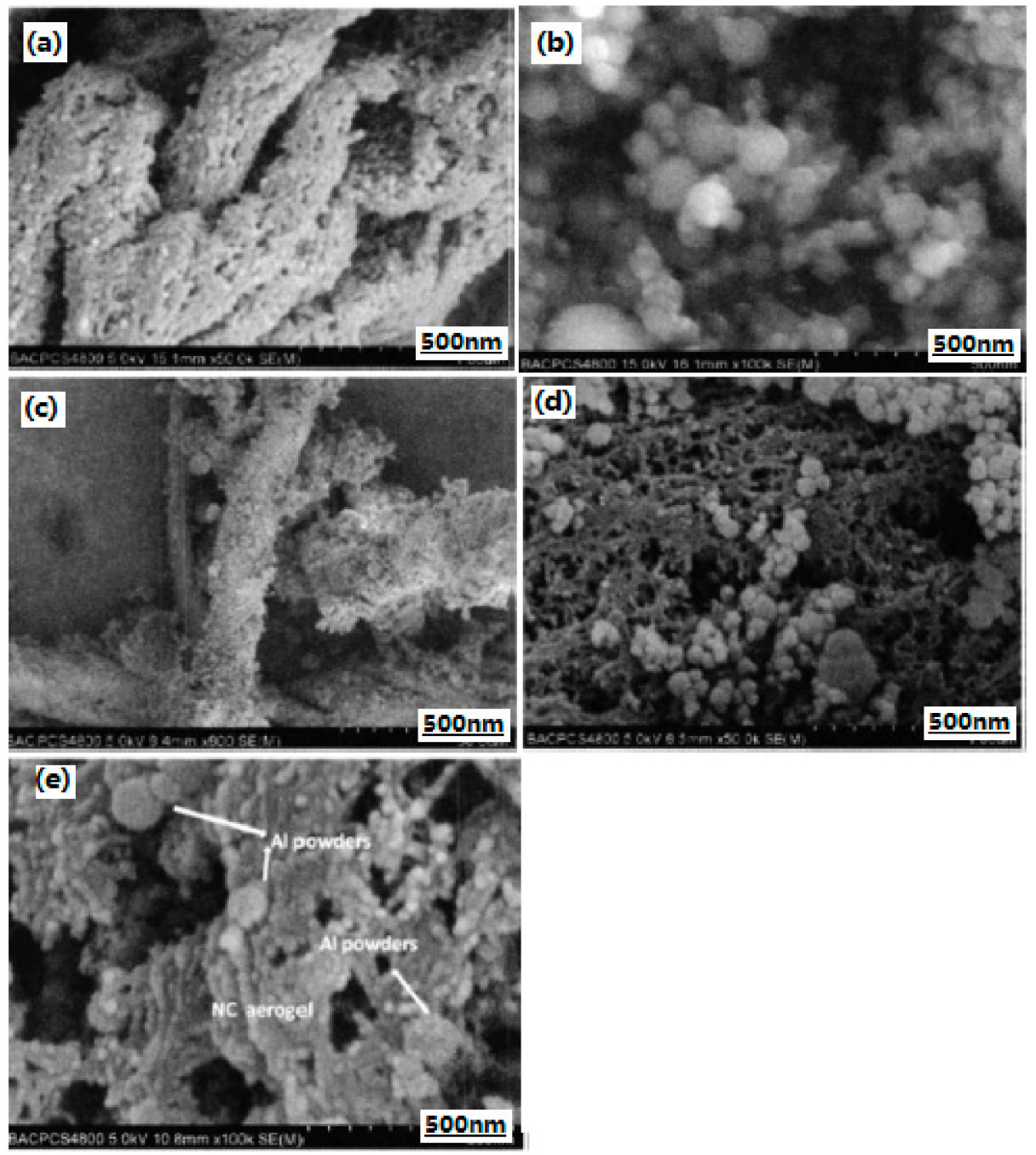

Figure 3. SEM images of different composite samples. (a) NC aerogel; (b) Al powder; (c) Al/NC mixture; (d) NC aerogel/Al mixture; and (e) Al/NC nano-sized composite. Reproduced from [33], with permission from Han Neng Cai Liao, 2013.
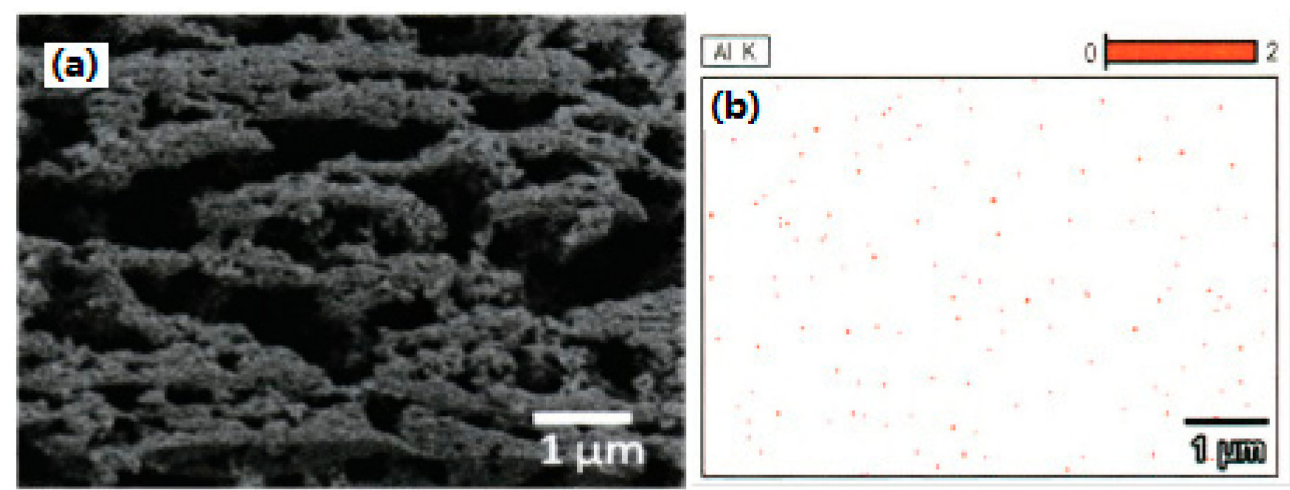

Figure 4. Al elements distribution of $\mathrm{Al} / \mathrm{NC}$ nano-composite $(\mathrm{Al} / \mathrm{NC}=1: 2)$ by $\mathrm{EDS}$ analysis. (a) Selected area of Al/NC nano-sized composite; (b) Al elements' distribution. Reproduced from [33], with permission from Han Neng Cai Liao, 2013. 


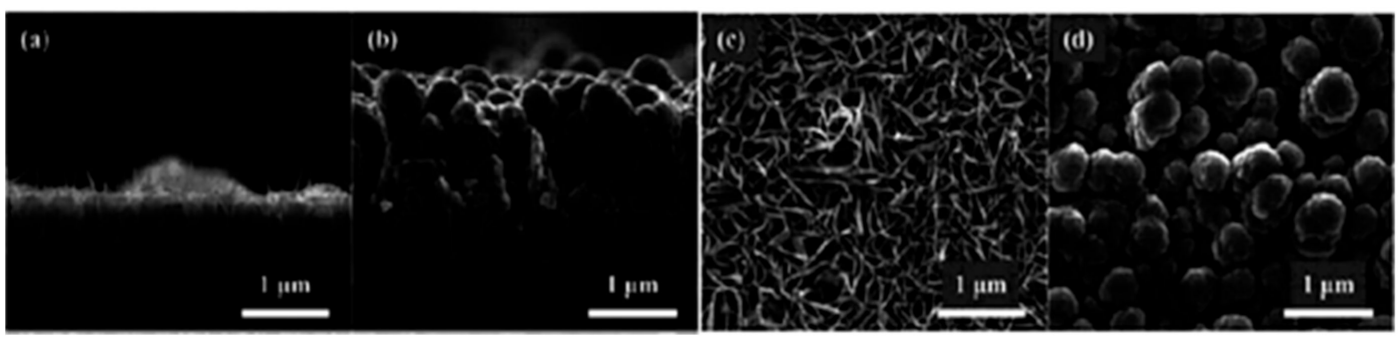

Figure 5. The cross-sectional and top-view SEM photos of $\mathrm{MnO}_{2}$ and $\mathrm{MnO}_{2} / \mathrm{Al}$ particles. (a) Cross-sectional of $\mathrm{MnO}_{2} ;$ (b) cross-sectional of $\mathrm{MnO}_{2} / \mathrm{Al}$; (c) top-view of $\mathrm{MnO}_{2}$; and (d) top-view of $\mathrm{MnO}_{2} / \mathrm{Al}$. Reproduced from [34], with permission from Initiators \& Pyrotechnics, 2018.

Additionally, $\mathrm{Al}$ powder with $500 \mathrm{~nm}, 1000 \mathrm{~nm}$, and $1500 \mathrm{~nm}$ thickness was deposited on $\mathrm{MnO}_{2}$ with 900 nm thickness, as samples S900-500, S900-1000, and S900-1500 were conducted (Figure 6). Thermal analysis shows that the nano-structured $\mathrm{Al} / \mathrm{MnO}_{2}$ energetic materials have a lower onset reaction temperature $\left(510^{\circ} \mathrm{C}\right)$ and relatively higher heat of reaction $\left(2380 \mathrm{~J} \cdot \mathrm{g}^{-1}\right)$ before $\mathrm{Al}$ melting. Hydrophobicity is achieved by coating a layer of fluorocarbon, indicating the possible long-term storage ability.

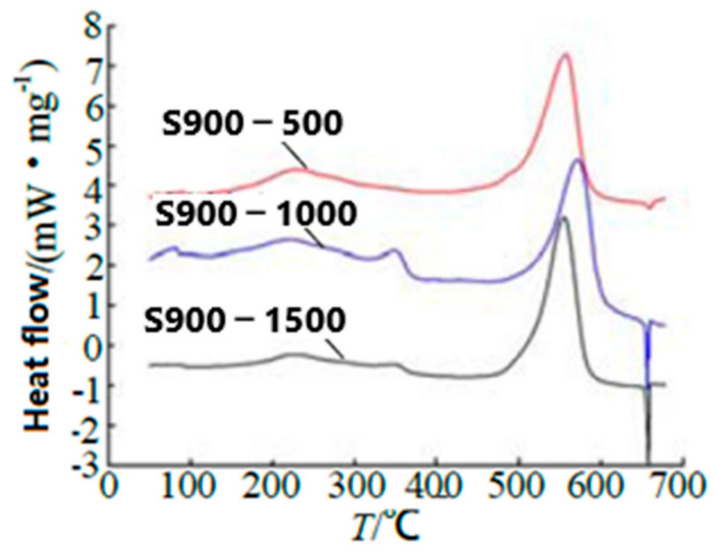

Figure 6. DSC curves of $900 \mathrm{~nm}$ thickness $\mathrm{MnO}_{2}$ samples with nominal $500 \mathrm{~nm}, 1000 \mathrm{~nm}$, and $1500 \mathrm{~nm}$ Al. Reproduced from [34], with permission from Initiators \& Pyrotechnics, 2018.

In order to improve the long-term storage stability, fluorocarbon compound was deposited on the surface of nano-sized $\mathrm{Al} / \mathrm{MnO}_{2}$ composite, which have nano texture structures. Figure 7 shows the SEM photos of $\mathrm{Al} / \mathrm{MnO}_{2} /$ fluorocarbon composite. It can be seen that the structure of $\mathrm{Al} / \mathrm{MnO}_{2}$ remained unchanged after the fluorocarbon coating, and the surface of the coated composite is better than that of coating before.
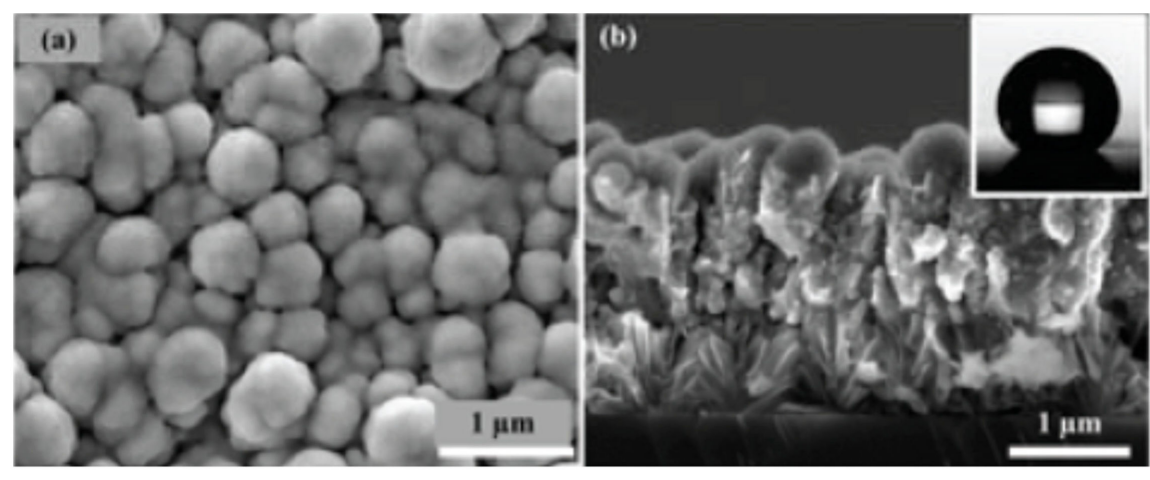

Figure 7. SEM photos of $\mathrm{MnO}_{2} / \mathrm{Al} /$ fluorocarbon composite. (a) Cross-sectional; (b) top-view. Reproduced from [34], with permission from Initiators \& Pyrotechnics, 2018. 


\subsubsection{Nano-Sized $\mathrm{Al} / \mathrm{CuO}$ Energetic Composite}

$\mathrm{CuO}$ is a good catalyst on the decomposition and combustion of solid propellant, as we know. In order to significantly enhance the energetic characteristics and long-term storage stability, two types of super-hydrophobic nano-sized $\mathrm{Al} / \mathrm{CuO}$ core/shell structured particles were prepared onto $\mathrm{Cu}$ foils, with $\mathrm{CuO}$ nano-rods or nano-tubes as the core and $\mathrm{Al}$ as the shell, combined with the solution chemistry method, magnetron sputtering, and surface treatments. Both nano-sized materials exhibit excellent thermal behaviors, especially for the hollow tube structured $\mathrm{Al} / \mathrm{CuO}$ nano-tubes. Moreover, the functionalized nano-sized $\mathrm{Al} / \mathrm{CuO}$ particles possess long-term storage stability for as high as $88 \%$ of energy left after being exposed in the air for one month, benefitting from the enhanced resistibility to the humid environment. Combustion analysis of functionalized $\mathrm{Al} / \mathrm{CuO}$ nanotubes is performed and the results reveal that the steady combustion process with the flame propagation speed is $100 \mathrm{~m} \cdot \mathrm{s}^{-1}$. This study can provide new ideas for maintaining the activity of nano-CEMs through surface functionalization and significativity for practical applications [35].

A method is disclosed for producing an energetic metastable nano-composite material. Under pre-selected milling conditions, a mixture of powdered components is reactively milled. These components will spontaneously react at a known duration of the pre-selected milling conditions [36]. The milled powder is recovered as a highly reactive nanostructured composite for subsequent use by controllably initiating destabilization thereof. On the basis of this method, several thermite powders with a nominal composition of $2 \mathrm{Al} \cdot 3 \mathrm{CuO}$ were prepared by arrested reactive milling using different milling times [37]. The powder particles comprise a fully dense Al matrix with $\mathrm{CuO}$ inclusions. The dimensions of the $\mathrm{CuO}$ inclusions are around $100 \mathrm{~nm}$ and are effectively the same for all prepared powders. The number of inclusions per unit of mass of the composite particles increases with the increased milling times, while unattached $\mathrm{CuO}$ particles are present in the samples prepared with shorter milling times. The redox reaction kinetics in the $\mathrm{Al} / \mathrm{CuO}$ thermites was described, and the multistep reaction model remains valid for composite powders prepared with different milling conditions, and thus characterized by different aluminum/copper oxide ratios. One point should be note that, to accurately describe the rate of redox reactions in specific nanocomposite powders, the model must account for the size of $\mathrm{CuO}$ inclusions and the number of inclusions per unit of mass in the nanocomposite particle.

\subsubsection{Nano-Sized $\mathrm{Al} / \mathrm{Co}_{3} \mathrm{O}_{4}$ Composite}

The energetic performance of nano-CEMs depends on the interfacial diffusion and mass transfer during the reacted process. However, the development of the desired structure to significantly enhance the reactivity still remains challenging for researchers. $\mathrm{Co}_{3} \mathrm{O}_{4}$ micro-spheres with $3 \mathrm{D}$ porous hollow were designed and prepared, in which gas-blowing agents (air) and maximized interfacial interactions were introduced to enhance the mass transport and reduce the diffusion distance between the oxidizer and fuel (aluminum) [38]. A low-onset decomposition temperature $\left(423^{\circ} \mathrm{C}\right)$ and high heat output $\left(3118 \mathrm{~J} \cdot \mathrm{g}^{-1}\right)$ were observed, resulting from porous and hollow nano-structure of $\mathrm{Co}_{3} \mathrm{O}_{4}$ micro-spheres. Furthermore, 3D hierarchical $\mathrm{Al} / \mathrm{Co}_{3} \mathrm{O}_{4}$ arrays were directly fabricated on the silicon substrate, which was fully compatible with silicon-based microelectromechanical systems to achieve functional nano-sized energetics-on-a-chip. This approach can provide a simple and efficient way to fabricate the 3D ordered nano-sized energetic arrays with superior reactivity, and it has potential applications in micro-energetic devices.

\subsubsection{Nano-Sized $\mathrm{Al} / \mathrm{MoO}_{3}$ Energetic Composite}

A monolayer of two-dimensional (2D) $\mathrm{MoO}_{3}$ with 3-4 $\mu \mathrm{m}$ thickness was prepared by the ultrasonic dispersion method, and then the nano-sized $\mathrm{Al} / \mathrm{MoO}_{3}$ composite with a high interface contact area by combining $\mathrm{Al}$ nanoparticles with $80 \mathrm{~nm}$ in diameter was prepared [39]. The combustion data show that the burning rate reaches $(1730 \pm 98.1) \mathrm{m} \cdot \mathrm{s}^{-1}$ for their high interface contact area, the increasing 
rate of pressure is $(3.49 \pm 0.31) \mathrm{MPa} \cdot \mathrm{s}^{-1}$, and the temperature in the reacted area is $3253 \mathrm{~K}$ [40]. This is the highest value for the nano-sized $\mathrm{Al} / \mathrm{MoO}_{3} \mathrm{CEMs}$ reported so far. At the same time, the $\mathrm{Al} / \mathrm{Fe}_{2} \mathrm{O}_{3}$ and other metal oxides-based energetic materials were coated on $\mathrm{Al} / \mathrm{Monel}$ (Monel nickel-based alloy), while $\mathrm{Ni} / \mathrm{Al}, \mathrm{Ni} / \mathrm{Si}$, and other laminated structural materials were prepared as well using the sol-gel method and multi-layer injection method; see details in [41].

Moreover, low-temperature redox reactions in nano-thermites prepared by arrested reactive milling (ARM) were described by the Cabrera-Mott (CM) mechanism, in which the growth of very thin oxide layers is accelerated by an electric field induced across such layers. A reaction mechanism combining the initial CM step with the following oxidation steps identified earlier for oxidation of $\mathrm{Al}$ and representing growth and phase transitions in various polymorphs of alumina was proposed and shown to be valid for different $\mathrm{Al} / \mathrm{CuO}$ nanocomposite powders prepared by $\mathrm{ARM}$. $\mathrm{Al} / \mathrm{MoO}_{3}$ nanocomposite was prepared by the similar multi-step reaction mechanism [42]. The powder particles comprise a fully dense $\mathrm{Al}$ matrix with nano-sized $\mathrm{MoO}_{3}$ inclusions. A weight loss representing dehydration of the composite material was observed at low-temperature thermogravimetry (TG) measurements. Kinetics of the initial exothermic redox reaction observed in both DSC and micro-calorimetry experiments could be successfully described by the CM mechanism. Reactions at elevated temperatures were also well described by the previously identified sequence of steps associated with phase changes and oxidation of various alumina polymorphs. A modification to the $\mathrm{CM}$ kinetics was necessary to describe an intermediate range of temperatures, between approximately 400 and $600 \mathrm{~K}$. This modification is suggested to represent a temperature induced change in the structure of a very thin precursor aluminum oxide layer separating $\mathrm{Al}$ and $\mathrm{MoO}_{3}$.

\subsubsection{Nano-Sized Al/Ni Energetic Composite}

As we know, under the stimulation of external conditions (such as heating, current, and laser), $\mathrm{Al} / \mathrm{Ni}$ composite can produce solid-solid exothermic reaction with a high temperature, and maintain the self-sustaining reacted process, forming the compounds between these two elements. Further, it has been used in the welding and ignition research fields [43]. On the basis of the high temperature and exothermic reaction of $\mathrm{Al} / \mathrm{Ni}$ composite with a large specific surface area of nano-sized particles, a new nano-structured $\mathrm{Al} / \mathrm{Ni}$ energetic composite on silicon (Si) substrate using the template method were prepared [44]. Figure 8 shows the SEM photo and DSC curve of the Al/Ni nano-sized composite. As can be seen, Ni nano-sized rods (50 $\mathrm{nm}$ in diameter) grow vertically on the substrate, and Al covers the surface of Ni nano-sized rods and is partially embedded into the array of Ni nano-sized rods to form an embedded nano-sized structure (Figure 8a). This kind of embedded nano-sized structure can increase the contact area between the reactants $(\mathrm{Al}$ and $\mathrm{Ni}$ ) and increase their solid-solid reaction rate. The ignition of nano-sized $\mathrm{Al} / \mathrm{Ni}$ composite was examined by a single pulsed laser irradiation technique, and the results show that the nano-sized $\mathrm{Al} / \mathrm{Ni}$ composite produces sparks for several milliseconds, which is advantageous to its explosion application. The $50 \%$ firing energy of the $\mathrm{Al} / \mathrm{Ni}$ energetic composite is $36.28 \mathrm{~mJ}$, with an energy density of $46.22 \mathrm{~mJ} \cdot \mathrm{mm}^{-2}$.

The core-shell shaped carbon coated nano-sized aluminum (nAl) in the atmosphere of $\mathrm{CH}_{4}$ and Ar gases by means of laser induction combined heating method was prepared [5]. It was shown that its core is crystalline aluminum and its shell is graphite like carbon. Most of the particles are spherical with a diameter of 20-60 $\mathrm{nm}$ (thickness is 3-8 nm). During the formation of core-shell shaped nano-sized $\mathrm{Al} / \mathrm{C}$ particles, owing to the low density of carbon and its poor solubility with aluminum, carbon atoms do not dissolve in the interior of the nanoparticles, but they are deposited on the surface of the nanoparticles.

Additionally, nano-sized Al-Ni energetic material with $90-100 \mathrm{~nm}$ particles is fabricated and the experimental results of its properties are presented [45]. High values of specific energy and the rate of its release make it possible to use this material as a heat release element in thermoelectric power generation devices. It has been demonstrated experimentally that it is possible to maintain a voltage 
value higher than $1 \mathrm{~V}$ for $45 \mathrm{~s}$ as a result of combustion of a $3 \mathrm{~g}$ Al-Ni sample, and that using a simple DC-DC converter will allow charging supercapacitors or accumulators.
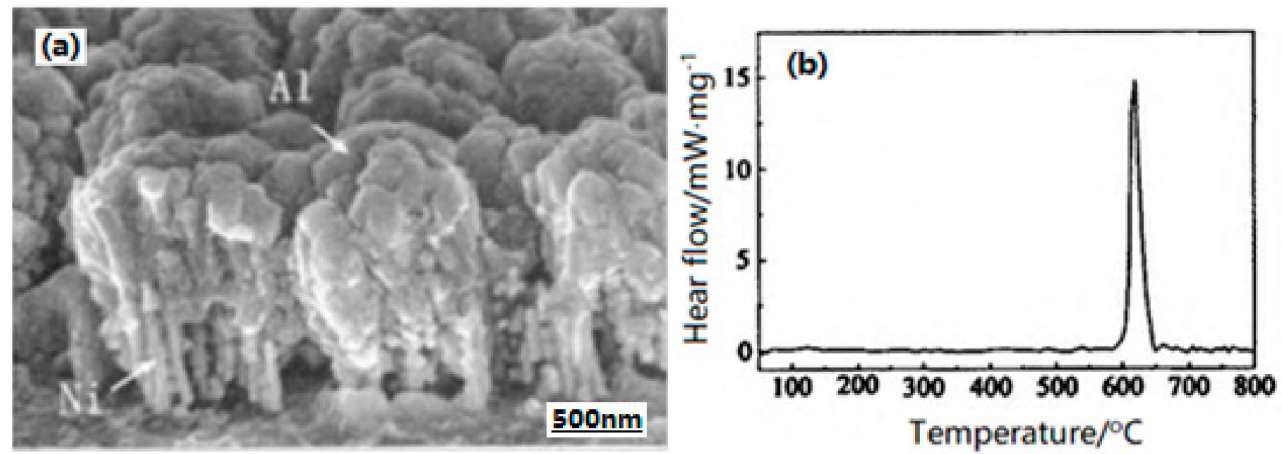

Figure 8. SEM and DSC curve of $\mathrm{Al} / \mathrm{Ni}$ nano-sized composite. (a) SEM of Al/Ni nano-sized composite; (b) DSC curve of Al/Ni nano-sized composite. Reproduced from [44], with permission from Huo Zha Yao Xue Bao, 2012.

\subsubsection{Nano-Sized Al/Fatty Acid Energetic Composite}

Aluminum-oleic acid composite nanoparticles with a mean diameter of $85 \mathrm{~nm}$ were successfully prepared by means of a wet chemical process [46]. The Al/oleic acid molar ratio affects the thickness of the oleic acid layer on $\mathrm{Al}$ nanoparticles. Al electrodes can be formed by firing an $\mathrm{Al}$ nanoparticle paste film at $600{ }^{\circ} \mathrm{C}$, and the firing temperature is about $300^{\circ} \mathrm{C}$ lower than that required for micrometer-sized $\mathrm{Al}$ particles. The electrode formed from commercial $\mathrm{Al}$ nanoaparticles is not electrically conducted because of the oxide layer $\mathrm{Al}$ nanoparticles; however, the film from the prepared $\mathrm{Al}$ nanoparticles for an $\mathrm{Al} / \mathrm{oleic}$ acid molar ratio of 1:0.05 has a minimum specific resistance of $5.6 \mathrm{~m} \Omega \cdot \mathrm{cm}$.

\subsubsection{Nano-Sized Al/Polymer Energetic Composite}

Polyimide (PI) composites with high dielectric permittivity have received a great deal of attention in embedded capacitors and energy-storage devices owing to its excellent thermal stability and good mechanical properties. Nano-aluminum $(\mathrm{Al})$ particles were introduced into PI to prepare promising $\mathrm{PI} /$ nano-Al composites [47]. The results indicate that the dielectric constant of the composite films increased with the increase of nano-Al contents, and the highest dielectric constant was 15.7 for a composite film incorporating $15 \mathrm{wt} \%$ nano-Al. The effects of mixture doping concentration on volume resistivity and loss tangent are analyzed. The correlation effects of the $\mathrm{Al}$ nanoparticles on the different factors that influence the dielectric performance in the PI matrix such as microstructure, resistivity, and interface of the composites were discussed in detail. This composite film would thus possess potential application in flexible energy-storage devices.

\subsection{Al-Based Ternary System}

\subsubsection{Nano-Sized $\mathrm{Al} / \mathrm{B} / \mathrm{Fe}_{2} \mathrm{O}_{3}$ Energetic Composite}

In order to reduce the acidic impurity of $\mathrm{B}_{2} \mathrm{O}_{3}$ and $\mathrm{H}_{3} \mathrm{BO}_{3}$ on the surface of amorphous boron powder and improve the efficiency of boron powder application, the nano-sized $\mathrm{Al} / \mathrm{B} / \mathrm{Fe}_{2} \mathrm{O}_{3}$ energetic composites were prepared through the high energy ball milling [48]. It was found in Figure 9 that the particle size of raw $\mathrm{Al}$ and $\mathrm{B}$ is micro-scale; with the increase of milling time, the average particle size of $\mathrm{Al} / \mathrm{B}$ bimetal composite decreases. This is because of the large plastic deformation of the two mixed powders in the composite at the initial stage of ball milling. In the physical mixed samples, the spherical particles of aluminum can still be seen. Boron powder and iron oxide are simply adsorbed onto the surface of aluminum powder, indicating that aluminum powder, iron oxide, and boron powder are simply blended, and the morphology of the grains has not changed. For the $\mathrm{Al} / \mathrm{B} / \mathrm{Fe}_{2} \mathrm{O}_{3}$ tri-metal composite, there are no spherical aluminum particles, flake boron powder, and flocculent iron oxide, 
which shows that these three components have been combined and the average particle size is about $90 \mathrm{~nm}$. The heat release of the prepared nano-sized $\mathrm{Al} / \mathrm{B} / \mathrm{Fe}_{2} \mathrm{O}_{3}$ composite increases with an increase in the mass fraction of B in the composition, as can be seen from the DSC curves in Figure 10.

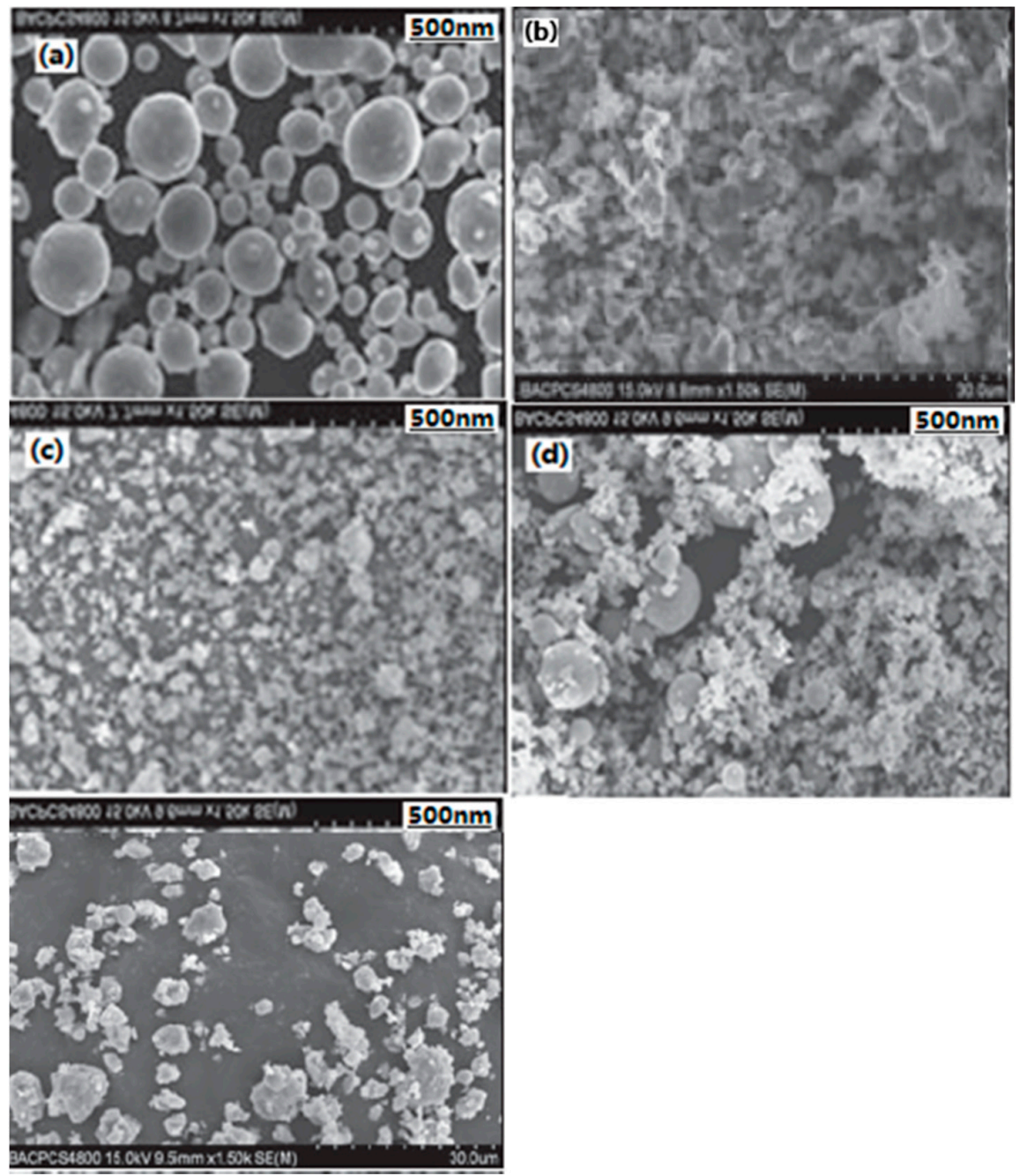

Figure 9. SEM photographs of different samples. (a) Raw Al; (b) raw B; (c) Al/B composite; (d) physical mixed; and (e) ball milling. Reproduced from [48], with permission from Gu Ti Huo Jian Ji Shu, 2014.

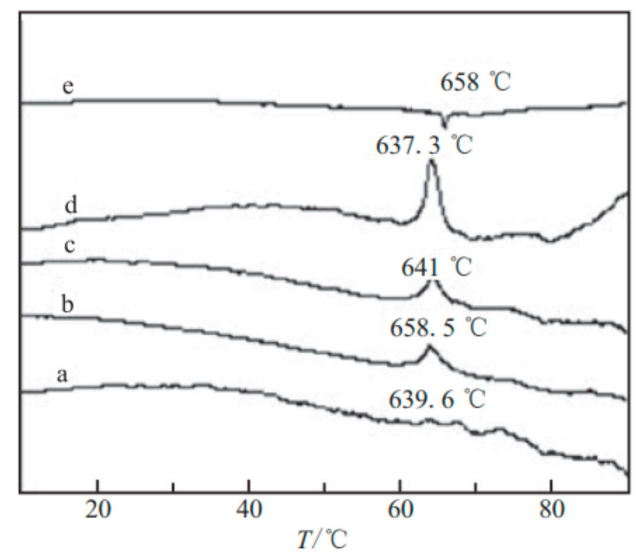

Figure 10. DSC of $\mathrm{Al} / \mathrm{B} / \mathrm{Fe}_{2} \mathrm{O}_{3}$ nano-sized composites. Reproduced from [48], with permission from $\mathrm{Gu}$ Ti Huo Jian Ji Shu, 2014. 


\subsubsection{Nano-Sized $\mathrm{Al} / \mathrm{CuO} / \mathrm{KClO}_{4}$ Energetic Composite}

A solvent/non-solvent synthetic approach was utilized in preparing nano-sized $\mathrm{Al} / \mathrm{CuO} / \mathrm{KClO}_{4}$ composite by coating $\mathrm{Al} / \mathrm{CuO}$ particles with a layer of nanoscale oxidizer $\mathrm{KClO}_{4}$. The results reveal that, after ball milling and the chemical synthesis process, the phase compositions were not changed. Scanning electron microscopy (SEM) images show that these energetic nano-sized composites consist of small clusters of $\mathrm{Al} / \mathrm{CuO}$ that are in intimate contact with a continuous and clear-cut $\mathrm{KClO}_{4}$ layer $(100-400 \mathrm{~nm})$. High $\mathrm{K} / \mathrm{Cl}$ intensity on the perimeter of the nano-sized particles and high $\mathrm{Al} / \mathrm{Cu}$ mass fraction in the interior powerfully demonstrated the $\mathrm{Al} / \mathrm{CuO} / \mathrm{KClO}_{4}$ core-shell nanostructure. Electrical ignition experiments and pressure cell test prove that these nano-sized energetic composites are more sensitive to ignition with a much higher burning rate than that of traditional formulations (conventional counterparts). The TG and DSC results show that the burning rate of these energetic nano-sized composites nearly tripled [49].

\subsubsection{Nano-Sized Al/B/Ni Energetic Composite}

In order to improve the dispersion of nano-sized catalyst particles in the propellant composition and make full use of its catalytic performance, nano-sized $\mathrm{Al} / \mathrm{B} / \mathrm{Ni}$ composites were prepared [50]. It can be seen that the surface of raw $\mathrm{Al}$ is smooth, and their average particle size is $20-30 \mathrm{~nm}$ (Figure 11a). The coated particles on the surface of nano-sized composite particles are uniform and continuous, and the smooth surface of core aluminum particles is not exposed, thus the coating is relatively complete, and most of their average particle sizes are $20-30 \mathrm{~nm}$, while a few are $50 \mathrm{~nm}$ (Figure 11b). Moreover, the proportion of $\mathrm{Ni} / \mathrm{B}$ alloy particles in the composite particles in the presence of original unit particles increased significantly, and the proportion of agglomerated particles decreased significantly, indicating that the preparation of nano-sized composite particles can improve its dispersion performance in the composition. It can be also found that a thin coating film is attached on the surface of aluminum powder, and the coating layer is uniform and continuous. There are two obscure rings (Figure 11d), which is similar to Figure 11c.
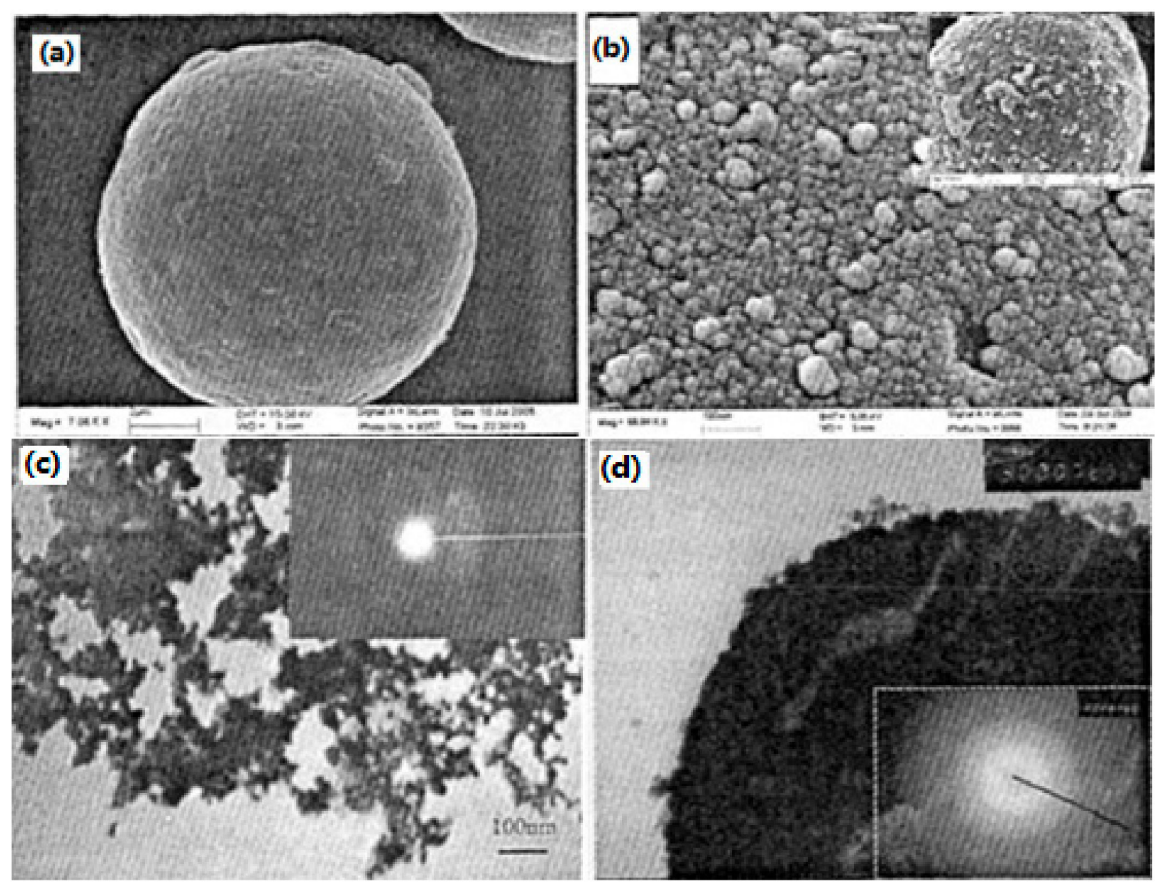

Figure 11. SEM and transmission electron microscopy (TEM) photographs of different samples. (a) Raw Al powder; (b) Al/B/Ni nano-sized composite particles. Reproduced from [36], with permission from Elsevier, 2016; (c) Ni/B nano-sized alloy; and (d) Al/B/Ni nano-sized composite particles. Reproduced from [50], with permission from Han Neng Cai Liao, 2009. 
A certain proportion of nano-sized Ni/B amorphous alloy and AP are ground and compounded on a planetary ball mill in the presence of a small amount of anhydrous ethanol, and then dried to obtain the nano-sized Ni/B composite particles and AP. Figure 12 shows the DTA (differential thermal analysis) curves of AP with different mass ratios of nano-sized Al/B/Ni composite particles, and the mass fraction data refers to the percentage of $\mathrm{Ni} / \mathrm{B}$ in $\mathrm{Ni} / \mathrm{B} / \mathrm{Al}$ and $\mathrm{AP}$ composites, which is $5 \%, 10 \%$, and $12 \%$, respectively. It is shown that, with the increase of the mass fraction of nano-sized $\mathrm{Ni} / \mathrm{B}$ particles, the exothermic peak temperature of AP decreases, indicating that the catalytic effect increased with an increase in the mass fraction of the nano-sized composite. However, when the mass fraction is more than $10 \%$, the exothermic peak temperature cannot continue to decline, and the decomposition speed decreases, indicating that the catalytic effect does not continue to increase with its mass fraction. Moreover, when the mass fraction of nano-sized Ni/B is $12 \%$, the exothermic peak temperature of composites is higher than that of pure AP at low-temperature range, indicating that nano-sized Ni/B particle hinders the low-temperature thermal decomposition of AP. Additionally, the minimum (or maximum) value of the quadratic curve equation is used to get the optimum amount of catalyst in the graph, as well as the fitting equation between the decomposition temperature and mass fraction of each sample in Figure 12, which is $y=1.363 x^{2}-21.625 x+475.77$, where the fitting coefficient is 0.97 , it was calculated that the optimum mass fraction of $\mathrm{Ni} / \mathrm{B}$ particles in $\mathrm{Al} / \mathrm{NiB}$ composite is $7.93 \%$, and the corresponding minimum temperature is $389.98{ }^{\circ} \mathrm{C}$ on the theoretical high-temperature decomposition, indicating that the catalytic effect of nano-sized particles has been improved significantly after treatment.

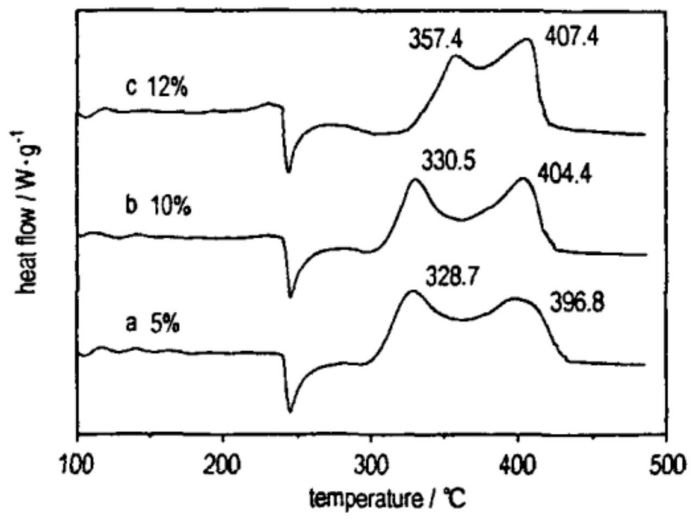

Figure 12. DTA curves of AP with different ratios of nano-sized $\mathrm{Al} / \mathrm{B} / \mathrm{Ni}$ composite particles. Reproduced from [50], with permission from Han Neng Cai Liao, 2009.

\subsubsection{Nano-Sized $\mathrm{Al} / \mathrm{RDX} / \mathrm{Fe}_{2} \mathrm{O}_{3}$ Energetic Composite}

The sol-gel method is one of the most important techniques for preparation of nano-sized particles, while nano-sized $\mathrm{Al} / \mathrm{RDX} / \mathrm{Fe}_{2} \mathrm{O}_{3}$ composites with a mass fraction of $85 \%$ hexogen (RDX), $3.75 \%$ aluminum, and $11.25 \%$ iron oxide $\left(\mathrm{Fe}_{2} \mathrm{O}_{3}\right)$ were prepared by sol-gel template and supercritical $\mathrm{CO}_{2}$ fluid drying technology, where mechanical sensitivity and detonation velocity were compared with those of pure RDX. Particles were characterized by scanning electron micro-scale (SEM) shown in Figure 13. $\mathrm{Fe}_{2} \mathrm{O}_{3}$ aerogel is a complete "honeycomb", which has a relatively uniform pore size, and the average pore size is between $50 \mathrm{~nm}$ to $100 \mathrm{~nm}$. When the initial particles are polymerized to form gel, the particles are combined to form a three-dimensional porous aerogel skeleton. After supercritical fluid drying, the liquid in the pores is taken away, forming the honeycomb structure of $\mathrm{Fe}_{2} \mathrm{O}_{3}$ (Figure 13a). A small amount of RDX grains are embedded on the surface of the crystal, and they are formed with the evaporation and diffusion of dimethylformamide (DMF) during the drying process. The structure of $\mathrm{Fe}_{2} \mathrm{O}_{3}$ colloid is broken and a small amount of RDX grains are exposed (Figure 13b). The nano-sized composites in high-resolution microscopic SEM photos exhibit a spherical or near-spherical shape, and the average particle size is in the range of 100-200 nm (Figure 13c). 

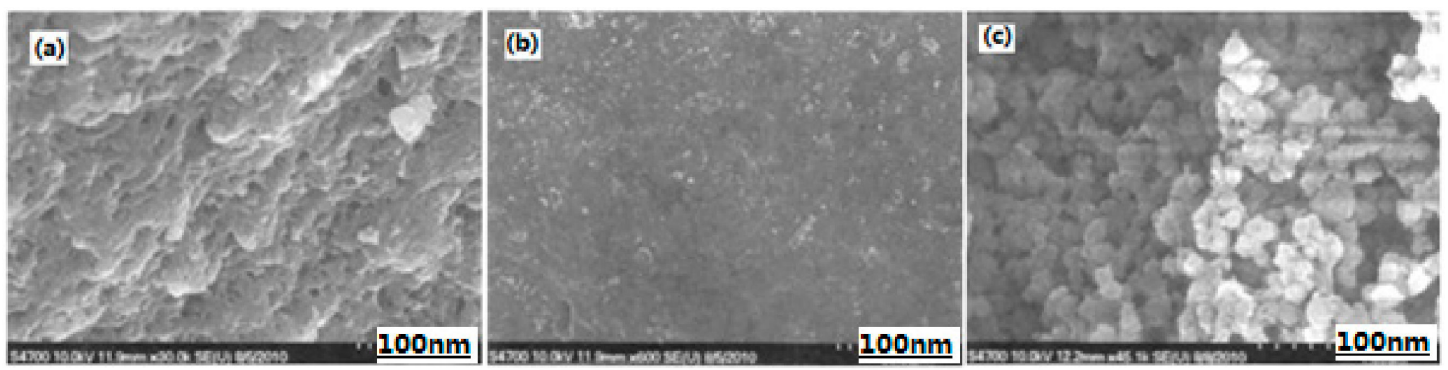

Figure 13. SEM photos of different particles. (a) $\mathrm{Fe}_{2} \mathrm{O}_{3}$ gas gel; (b) lowresolution microscopic of $\mathrm{Al} / \mathrm{RDX} / \mathrm{Fe}_{2} \mathrm{O}_{3}$ composite; and (c) high-resolution microscopic of $\mathrm{Al} / \mathrm{RDX} / \mathrm{Fe}_{2} \mathrm{O}_{3}$ composite. Reproduced from [51], with permission from Han Neng Cai Liao, 2011.

For this formation mechanism of nano-sized composite, DMF solution of the explosive is filled inside the gel mesh in the process of forming $\mathrm{Fe}_{2} \mathrm{O}_{3}$ gel, and the $\mathrm{nAl}$ powder is evenly dispersed in the gel system by ultrasonic vibration instrument. Using the supercritical fluid drying technology by the super solubility and diffusivity of supercritical $\mathrm{CO}_{2}$ fluid, $\mathrm{RDX}$ rapidly recrystallizes around the $\mathrm{nAl}$ powder in the gel hole, which suppressed the further crystallization and growth of RDX effectively. The nano-CEMs were formed from nano-sized RDX and nAl powder encapsulated by $\mathrm{Fe}_{2} \mathrm{O}_{3}$ colloid.

Under the same experimental conditions, the impact sensitivity and friction sensitivity of nano-sized $\mathrm{Al} / \mathrm{RDX} / \mathrm{Fe}_{2} \mathrm{O}_{3}$ composites are much lower than that of pure RDX (Table 1). This can be related to the "hot spot" formation of the samples during the test process. On the one hand, the grains of nano-sized composites are much smaller, its surface structure integrity is good, and there are few defects, which make it difficult to form local "hot spots" inside. On the other hand, nano-sized particles also have a unique lubrication effect, reducing the friction between the particles effectively, thus the smaller size of the "hot spot" decreases the mechanical sensitivity. The detonation velocity of nano-sized composites is $7185 \mathrm{~m} \cdot \mathrm{s}^{-1}$, which is higher than that of pure RDX by $615 \mathrm{~m} \cdot \mathrm{s}^{-1}$. This may be because of the difference between the nano-sized composites and the micro-scale mixed explosives. The mass transfer rate between the explosives or between explosive and metal for micro-scaled explosives is slow, while nano-scaled energetic transfer between explosive particles would not be affected by the mass transfer rate, which contributes to the high detonation velocity [51].

Table 1. Hazardous properties of RDX and different compositions.

\begin{tabular}{ccccc}
\hline Samples & $\begin{array}{c}\text { Impact } \\
\text { Sensitivity/cm }\end{array}$ & $\begin{array}{c}\text { Standard } \\
\text { Deviation }\end{array}$ & $\begin{array}{c}\text { Friction } \\
\text { Sensitivity/\% }\end{array}$ & $\begin{array}{c}\text { Detonation } \\
\text { Velocity/m· } \mathbf{s}^{\mathbf{1}}\end{array}$ \\
\hline $\mathrm{RDX}$ & 22.5 & 0.04 & 96 & 6570 \\
$\mathrm{Al} / \mathrm{RDX} / \mathrm{Fe}_{2} \mathrm{O}_{3}$ & 50.2 & 0.05 & 7 & 7185 \\
\hline
\end{tabular}

Note: impact sensitivity test condition: sample mass is $(35 \pm 1) \mathrm{mg}$, drop weight is $2.5 \mathrm{~kg}$, and relative huimidity is $\leq 80 \%$ at room temperature; friction sensitivity test condition: swing angle is $(90 \pm 1)^{\circ}$, gage pressure is $3.92 \mathrm{MPa}$, and sample mass is $(20 \pm 1) \mathrm{mg}$; detonation velocity test condition: sample shape is $\Phi 10 \mathrm{~mm} \times 10 \mathrm{~mm}$ and density is $1.55 \mathrm{~g} \mathrm{~cm}^{-3}$.

In order to compare the properties with $\mathrm{Al} / \mathrm{RDX} / \mathrm{Fe}_{2} \mathrm{O}_{3}$, nano-sized $\mathrm{B} / \mathrm{RDX} / \mathrm{Fe}_{2} \mathrm{O}_{3}$ (mass ratio is 2:90:8) composites were prepared by adding RDX and B powder into the gel template of $\mathrm{Fe}_{2} \mathrm{O}_{3}$, which were prepared by the sol-gel process and dried by supercritical $\mathrm{CO}_{2}$ fluid drying technology [52]. The results indicate that the average particle size of nanocomposite energetic material is $30-50 \mathrm{~nm}$. Compared with the pure RDX, the onset thermal decomposition temperature of $\mathrm{B} / \mathrm{RDX} / \mathrm{Fe}_{2} \mathrm{O}_{3}$ increases by $7{ }^{\circ} \mathrm{C}$, the reaction heat increases by $885 \mathrm{~J} \cdot \mathrm{g}^{-1}$, and the impact sensitivity (characteristic drop height, $\left.H_{50}\right)$ is $40.8 \mathrm{~cm}$.

\subsubsection{Nano-Sized Al/RDX/SiO 2 Energetic Composite}

With the continuous improvement of the performance requirements for energetic materials, RDX is one of the most widely used single explosives. In order to reduce the mechanical sensitivity of RDX and 
improve its thermal decomposition performance, three types of $\mathrm{Al} / \mathrm{RDX} / \mathrm{SiO}_{2}$ with $30 \%, 50 \%$, and $70 \%$ of $\mathrm{Al} / \mathrm{RDX}$ in the composites were prepared by means of the sol-gel method (Figure 14). In Figure 14a, $\mathrm{SiO}_{2}$ shows a cellular network structure. Granular Al/RDX is filled in only a few holes in the $\mathrm{SiO}_{2}$ skeleton, owing to the small proportion of Al/RDX (Figure 14b). With the increase of the Al/RDX mass fraction, the filling amount of $\mathrm{Al} / \mathrm{RDX}$ in the $\mathrm{SiO}_{2}$ skeleton increased significantly, and only few holes are not filled in (Figure 14c). All holes in the $\mathrm{SiO}_{2}$ skeleton are filled by Al/RDX, which leads to the obvious accumulation of Al/RDX particles in the skeleton (Figure 14d).
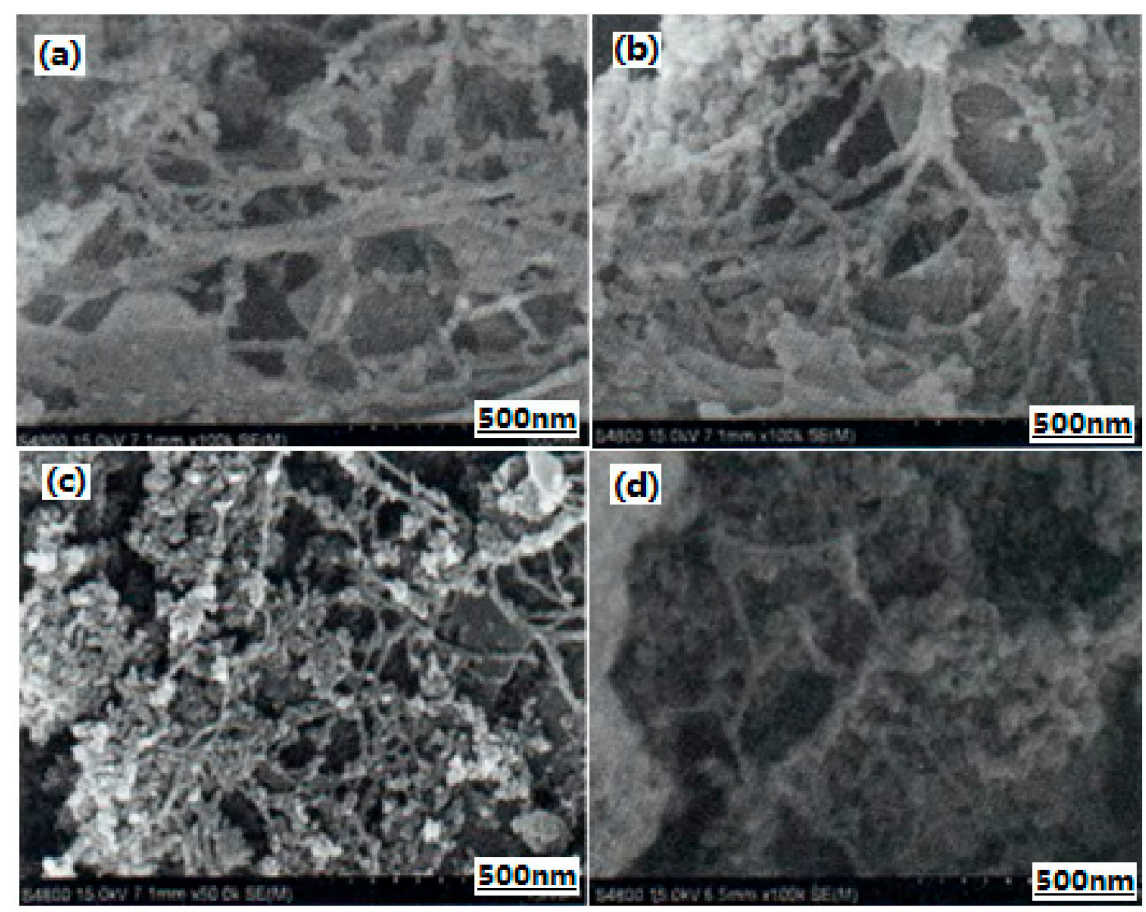

Figure 14. $\mathrm{SEM}$ photos of $\mathrm{SiO}_{2}$ xerogel and nano-sized $\mathrm{Al} / \mathrm{RDX} / \mathrm{SiO}_{2}$ composite particles. (a) $\mathrm{SiO}_{2}$ xerogel; (b) $30 \%$; (c) $50 \%$; (d) $70 \%$. Reproduced from [53], with permission from Han Neng Cai Liao, 2017.

On the basis of the preparation of nano-sized $\mathrm{Al} / \mathrm{RDX} / \mathrm{SiO}_{2}$ composite particles, its effects on the thermal decomposition of RDX were investigated by DSC and TG techniques at the heating rate of $10^{\circ} \mathrm{C} \cdot \mathrm{min}^{-1}$ (Figure 15). The melting and thermal decomposition peak temperatures of RDX in the prepared nano-sized $\mathrm{Al} / \mathrm{RDX} / \mathrm{SiO}_{2}$ composite materials are $1.56-4.49^{\circ} \mathrm{C}$ and $18.9-22.4{ }^{\circ} \mathrm{C}$, respectively, which are earlier than those of pure RDX (Figure 15a). With the increase of Al/RDX mass fraction in the $\mathrm{SiO}_{2}$ skeleton, the decomposition peak temperature with heat release of RDX increases gradually in the composite. This may be because, with the increase of Al/RDX mass fraction in the composition, the $\mathrm{SiO}_{2}$ skeleton is relatively reduced, and the agglomeration and accumulation of fillers occur in the skeleton, which results in the decrease of contact area between the reactants, thus the exothermic decomposition peak temperature of RDX in composites slightly increases on the macro-scale. Moreover, with the increase of $\mathrm{Al} / \mathrm{RDX}$ mass fraction in nano-sized $\mathrm{Al} / \mathrm{RDX} / \mathrm{SiO}_{2}$ composites, the mass loss of RDX in the composites is gradually delayed (Figure 15b). The reason may be that, with the increasing mass fraction of $\mathrm{Al} / \mathrm{RDX}$ filler in the $\mathrm{SiO}_{2}$ framework, some holes in the $\mathrm{SiO}_{2}$ framework are filled unevenly, collapse, and grain agglomeration, which reduces the contact area between the reactants. The mass transfer and heat transfer in the chemical reaction process are adversely affected, which is reflected in the TG curves (Figure 15b), that is, the mass loss of RDX in nano-sized Al/RDX/SiO 2 composites increased with the increase of the Al/RDX mass fraction. 

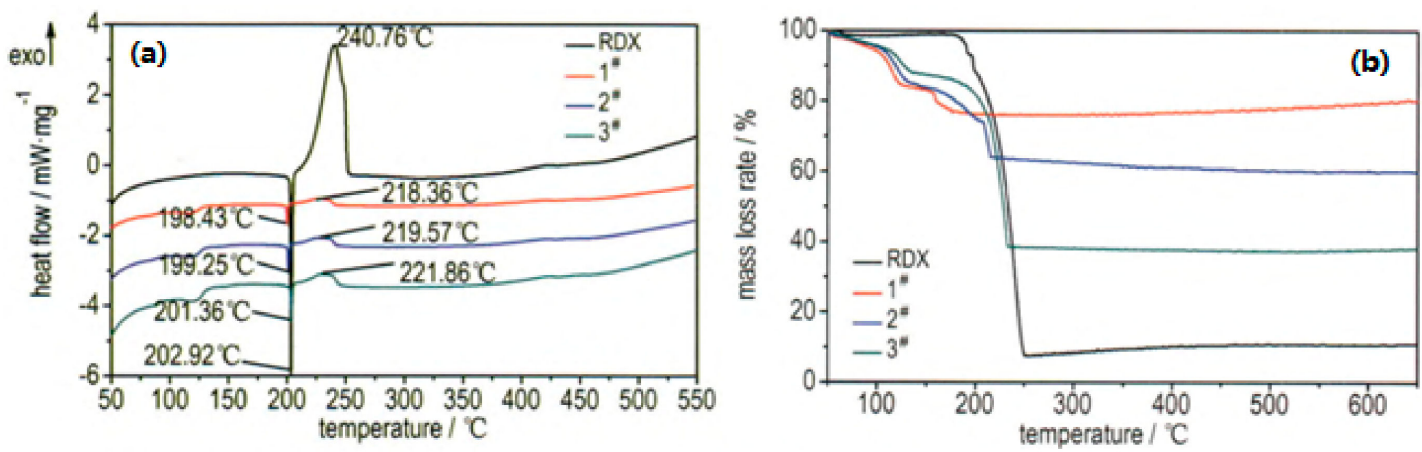

Figure 15. DSC (a) and TG (b) curves of pure RDX and nano-sized $\mathrm{Al} / \mathrm{RDX} / \mathrm{SiO}_{2}$ composite particles. $1 \#$ is $30 \%, 2 \#$ is $50 \%$, and $3 \#$ is $70 \%$. Reproduced from [53], with permission from Han Neng Cai Liao, 2017.

At the same time, the mechanical sensitivities of nano-sized $\mathrm{Al} / \mathrm{RDX} / \mathrm{SiO}_{2}$ composites were tested, which were compared with the particles by means of mechanical mixed procedure. The friction sensitivity and impact sensitivity of nano-sized $\mathrm{Al} / \mathrm{RDX} / \mathrm{SiO}_{2}$ composites $(26-68 \%, 27.1-95.6 \mathrm{~cm})$ is much lower than those of pure RDX $(10 \%, 134.9 \mathrm{~cm})$ and mechanical mixed ones $(74-85 \%, 18.6-25.1 \mathrm{~cm})$.

In order to improve the combustion of $\mathrm{RDX} / \mathrm{Al} / \mathrm{SiO}_{2}$ composites, nano-sized $\mathrm{Al} / \mathrm{RDX} / \mathrm{AP} / \mathrm{SiO}_{2}$ composites were prepared and characterized [54]. As shown in Figure 16a, the morphology of the spherical composite is uniform, the average particle size (higher than $200 \mathrm{~nm}$ ) and gradation are reasonable, and their accumulation is close. During the dry process, as the solvent evaporates, the gel pores collapse gradually. AP and RDX with solvent diffuse from one gel hole to another gel hole or gel surface (Figure 16b). For the gel complex by the supercritical drying process (Figure 16c), supercritical $\mathrm{CO}_{2}$ rapidly penetrates into the gel hole and extracts the organic solvents instantaneously, so that a large number of AP and RDX can crystallize rapidly in each gel hole. Supercritical $\mathrm{CO}_{2}$ has super solubility and diffusivity, which can effectively inhibit the diffusion and transfer of RDX between adjacent gel pores, thereby maintaining the integrity of the gel void structure.
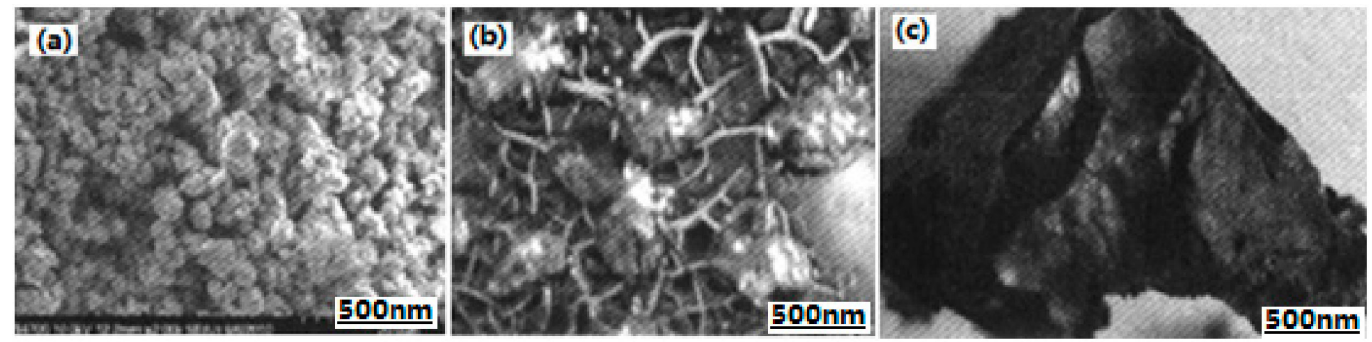

Figure 16. SEM photos of different particles. (a) Nano-sized $\mathrm{Al} / \mathrm{RDX} / \mathrm{AP} / \mathrm{SiO}_{2}$ composite; (b) gel complex by vacuum freeze drying; and (c) gel complex by supercritical drying. Reproduced from [55], with permission from Nanjing University of Science and Technology, 2018.

Moreover, the mechanical sensitivities of nano-sized $\mathrm{Al} / \mathrm{RDX} / \mathrm{AP} / \mathrm{SiO}_{2}$ composites were tested, which were compared with the particles by means of mechanical mixed procedure. The impact sensitivity of nano-sized $\mathrm{Al} / \mathrm{RDX} / \mathrm{SiO}_{2}$ composites $(48.3 \mathrm{~cm}$ ) is much lower than that of the mechanical mixed one $(30.7 \mathrm{~cm})[55]$.

In addition, nano-sized $\mathrm{Al} / \mathrm{AP}$ composites were prepared by means of the freeze-drying process by Martin et al., nAl powder was added to AP solution, and then the mixture solution was quickly poured into the container filled with liquid nitrogen to obtain the low-density nano-sized Al/AP composites, which improve the combustion performance of propellants [56,57]. 


\subsection{Properties and Applications of Typical Nano-CEMs}

At present, most studies use organic solvent as dispersant to disperse nAl powder and oxide. Considering the high activity of $\mathrm{nAl}$ and high flammability in the organic solvent, the preparation process is very dangerous. One alternative method is to use water as the dispersant. Because of the high activity of $\mathrm{nAl}$, the $\mathrm{nAl}$ powder can still react with water, resulting in the decrease of activity, although the surface is passivated by a layer of oxide [58,59]. It was found that, based on silane or oleic acid, the organic surface coating can effectively inhibit the reaction between $\mathrm{nAl}$ powder and water, ensuring its activity in a long period of time.

The impact ignition energy of nano-sized $\mathrm{Al} / \mathrm{MoO}_{3}$ composites is $0.3-1.7 \mathrm{~J}$, which increases with an increase in the particle size. The maximum reaction rate is related to the initial particle size, and the reaction rate increases with the decrease of the particle size. The combustion mechanism and reaction properties of four types of nano-sized $\mathrm{Al} / \mathrm{MoO}_{3}, \mathrm{Al} / \mathrm{WO}_{3}, \mathrm{Al} / \mathrm{CuO}$, and $\mathrm{Al} / \mathrm{Bi}_{2} \mathrm{O}_{3}$ composites were conducted; it was found that the propagation speed depends on the generation of gas and the thermodynamic state of reaction products, and the burning rate decreases with the increase of mixture density, which is contrary to the traditional explosion theory, so the combustion propagation mechanism is different from that of the traditional explosion theory. Nano-sized $\mathrm{Al} / \mathrm{Cr}_{2} \mathrm{O}_{3}$ with $10-15 \mathrm{~nm}$ in diameter was prepared, and the relationship between particle size and combustion performance by means of $\mathrm{CO}_{2}$ laser ignition technique was conducted; the performance is significantly improved compared with that of micro-scaled particles. One interesting point is that nano-sized $\mathrm{Al} / \mathrm{WO}_{3} \cdot \mathrm{H}_{2} \mathrm{O}$ composites were prepared by means of the wet chemical method, and its performance was compared with that of nano-sized $\mathrm{Al} / \mathrm{WO}_{3}$ composites; it was found that the energy release rate of reaction of $\mathrm{Al} / \mathrm{WO}_{3} \cdot \mathrm{H}_{2} \mathrm{O}$ is significantly improved by the reaction between $\mathrm{nAl}$ and $\mathrm{H}_{2} \mathrm{O}$ in $\mathrm{WO}_{3} \cdot \mathrm{H}_{2} \mathrm{O}$ to produce hydrogen, which increased the total heat release and energy release rate of the reaction.

Three nanocomposite materials with the same nominal stoichiometric thermite composition of $\mathrm{Al} / \mathrm{CuO}$ were prepared by three different methods: ultrasonic mixing (USM) of constituent nanopowders, electrospraying (ES), and arrested reactive milling (ARM). The combustion performances of the three prepared types of $\mathrm{Al} / \mathrm{CuO}$ nanocomposites were conducted [60]. Prepared powders were placed in a $6.7 \mathrm{~mm}$ diameter, $0.5 \mathrm{~mm}$ deep cavity in a brass substrate and ignited by electro-static discharge. The experiments were performed in air, argon, and helium. The mass of powder removed from the sample holder after ignition was measured in each test. Using a multi-anode photo-multiplier tube coupled with a spectrometer, time-resolved light emission traces produced by the ignited samples were recorded in the range of wavelengths of 373-641 nm. Time-resolved temperatures were then determined by fitting the recorded spectra assuming Planck's black body emission. Temporal pressure generated by ignition events in the enclosed chamber showed that the powder's combustion properties were tied to both their preparation technique as well as the environment in which they were ignited. The agglomeration of nanoparticles hindered the combustion of USM powders, while it was not observed for the ES powders. Lower temperatures and pressures were observed in oxygen-free gas environments for USM and ES powders prepared using starting nano-particles. For the ES powders, the effect of gas environment was less significant, which was interpreted considering that ES materials included gasifying nitrocellulose binder, enhancing heat, and mass transfer between individual Al and $\mathrm{CuO}$ particles. Higher pressures and temperatures were observed in inert environments for the ARM-prepared powder.

Addition of reactive nanocomposite powders can increase the burn rate of aluminum, and thus the overall reaction rate of the energetic formulation. Replacing only a small fraction of the fuel by a nanocomposite material can enhance the reaction rate with little change to the thermodynamic performance of the formulation. The nanocomposite materials $\mathrm{Al} / 3 \mathrm{CuO}$ and $\mathrm{Al} / \mathrm{MoO}_{3}$ prepared by $\mathrm{ARM}$, a scalable "top-down" technique for manufacturing reactive nano-materials, were added to micron-sized aluminum powder and the mixture was aerosolized and burned in a constant volume chamber with varied oxygen, nitrogen, and methane atmosphere [61]. The resulting pressure traces were recorded and processed to compare different types and amounts of modifiers. Additives of 
nanocomposite powders of $\mathrm{Al} / \mathrm{MoO}_{3}$ to micron-sized aluminum were found to be effective in increasing both the rate of pressure rise and maximum pressure in the respective constant volume explosion experiments. It was observed that $20 \mathrm{wt} \%$ of additive resulted in the best combination of the achieved burn rate and pressure.

The potential application of nano-aluminum/nitrocellulose mesoparticles as an ingredient for solid composite rocket propellants was investigated [62]. The basic strategy is to incorporate nanoaluminum in the form of a micrometer scale particle containing a gas-generator, to enable easier processing and potential benefits resulting from reduced sintering prior to combustion. The mesoparticles were made by electrospray and comprised aluminum nanoparticles $(50 \mathrm{~nm})$ and nitrocellulose to form micrometer scale particles. Eighty percent solids loaded composite propellants (AP/HTPB (hydroxilterminated polybutadiene) based) were made with the addition of micrometer sized $(2-3 \mu \mathrm{m})$ aluminum $(10 \mathrm{wt} \%)$, and compared directly to propellants made by directly substituting aluminum mesoparticles for traditional micrometer sized particles. The propellant burning rate was relatively insensitive for mesoparticles containing between $5 \mathrm{wt} \%$ and $15 \mathrm{wt} \%$ nitrocellulose. However, direct comparison between a mesoparticle-based propellant and a propellant containing micrometer scale aluminum particles showed burning rates approximately 35\% higher, while having a nearly identical burning rate exponent. High-speed imaging indicates that propellants using mesoparticles have less agglomeration of particles on the propellant surface.

The results show that the burning rate of nano-CEMs is the fastest when the particle size of $\mathrm{Al}$ powder and oxide is at nano-metric level, while the burning rate of CEMs composed of micron $\mathrm{Al}$ powder and nano-metric oxide is much faster than that of nanometer Al powder and micro-metric level.

\section{Conclusions and Future Challenges}

As one of new type of functional material, nano-sized composite energetic materials (nano-CEMs) have broad application prospects. However, most of the studies are carried out at the theoretical and laboratory level at present, which is still a long way from engineering and practical application. In the research field of high-energy explosives, the nano-sized composite process can cause the surface of each component of explosive to fully contact each other. On the one hand, it can decrease the agglomeration of ultrafine particles in explosives or improve the physical and chemical properties of explosives. On the other hand, it can also adjust the sensitivity of explosives and improve the safety performance of explosives. In the research field of solid propellants, using the nano-sized composite synthesis technologies, the powder and ultrafine catalyst are prepared into ultrafine composite particles, which can increase the contact area, improve the actual catalytic ability of the catalyst, and then greatly improve the energy release efficiency of the powder [63].

Nano-sized composite energetic materials (nano-CEMs) possess the characteristics of high energy density, high combustion rate of a few kilometers/second, and micron scale critical reaction propagation size. They have shown good application potential in many aspects, such as micro electro mechanical systems (MEMS) devices, anti-infrared decoy materials, and high energy additives. In addition, the combination between oxidants and reducers exhibits unique reaction dynamics characteristics at nano-scale, such as particle size dependence, mass transfer diffusion, energy release, and other mechanisms, which are quite different from the traditional micro-sized scale solid-state reaction. In the past years of study, significant progresses have been made in developing preparation methods, investigating properties, fundamental theory, and applications of nano-CEMs. However, the following difficult challenges to be addressed in the future have been identified.

(1) Understanding of reaction propagation mechanism of nano-CEMs is still in its infancy.

On the basis of the "melting diffusion mechanism" and "metal oxygen turnover mechanism", only the mass diffusion and reaction rate at the interface were considered, which can simply help us to understand the escape of oxygen atom $(\mathrm{O})$ in oxide at the initial stage (ignition stage) of reaction and the process of combining with active metal. In fact, the reaction propagation mechanism is more complicated after ignition during combustion. In the face of this challenge with complex and multiple 
factors, an effective strategy is to combine the experiment and theoretical model by peeling off the single influencing factor. However, these models are too simple, and there are few experiments to describe the multiple factors $[1,2,64-67]$. Thus, the understanding of the ignition and reaction propagation mechanism of nano-CEMs still requires the joint efforts of colleagues all over the world.

(2) The performance breakthrough is also limited by loading density, stability, and other factors.

Although nano-CEMs have high bulk energy density, it is difficult to obtain the ideal output energy, such as high pressure and shock wave owing to the lack of gas release within the reaction products. In order to obtain a high burning rate, it is necessary to heat the air between the powder voids to accelerate the convection and mass transfer, which significantly increases the dependence of reaction speed and loading density. Although the reaction speed can be slightly increased by the design of hollow spheres, branch, and other microstructures, it is difficult to balance the contradiction between the high bulk density and reaction rate of the composition. The reaction speed of the composition could be slightly improved by introducing gas products through nano-CEMs' composition design. However, it will bring new problems, such as stability and storage performance [1,2,37-39].

(3) Engineering application needs new breakthroughs and deep investigations.

Because most nano-CEMs use highly active nano-sized metals (such as $\mathrm{Al}, \mathrm{Mg}$ ) as reducing agents, how to avoid or reduce the self-oxidation of the highly active metals is the prime problem in engineering applications. For nano-sized aluminum powder, it is easy to agglomerate and influence its dispersion compositions by coating nano Al powder with polymer or other inert materials. In addition, in order to ensure the coating quality, the mass fraction of the inert coating materials is often high, which would reduce the energy density of the composition and increase the complexity of the reaction. In the process of formulation design, it is very difficult to bond the nano-CEMs with high specific surface area using the few mass fractions of binder [1,2,41-45], which is one of the common problems of nano-CEMs in the practical application.

Author Contributions: Conceptualization, W.P. and X.F.; resources, W.P., H.X., and K.W.; data curation, W.P.; writing-Original draft preparation, W.P.; writing—Review and editing, Y.C.; project administration, F.Z. and W.P.; funding acquisition, F.Z. and Z.Q. All authors have read and agreed to the published version of the manuscript.

Funding: This research was funded by "National Natural Science Foundation of China, grant number 21703167" and "Science and Technology on Combustion and Explosion Laboratory Foundation of China, grant number 2019SYSZCJJ".

Acknowledgments: The authors are thankful to Juan Zhao from Analysis and Measurement Center on Energetic Materials, Xi'an Modern Chemistry Research Institute for the particle micrograph experiments and Xiao-ning Ren from Science and Technology on Combustion and Explosion Laboratory, Xi'an Modern Chemistry Research Institute for the thermal decomposition tests. We are specially thankful to Luigi T. De Luca from Politecnico di Milano, Italy and Djalal Trache from Ecole Militaire Polytechnique, Algeria for providing many helpful suggestions and English statements.

Conflicts of Interest: The authors declare no conflict of interest. The funders had no role in the design of the study; in the collection, analyses, or interpretation of data; in the writing of the manuscript; or in the decision to publish the results.

\section{References}

1. He, W.; Liu, P.-J.; He, G.-Q.; Go, M.; Yan, Q.-L. Highly reactive metastable intermixed composites (MICs): Preparations and characterizations. Adv. Mater. 2018, 30, 1706293. [CrossRef] [PubMed]

2. Pang, W.-Q.; Fan, X.-Z.; Zhang, Z.-P. Nano-Sized Metal Powder: Preparation, Characterization and Energetic Application; National Defense Industry Press: Beijing, China, 2016.

3. An, T.; Zhao, F.-Q.; Hao, H.-X.; Ma, H.-X.; Yao, E.-G.; Yang, Y.; Tan, Y. Effect of thermites on laser ignition characteristics of double base propellants. Chin. J. Explos. Propellants 2011, 34, 67-72.

4. An, T.; Zhao, F.-Q.; Gao, H.-X.; Hao, H.-X.; Ma, H.-X. Sensitivity characteristics of double base propellants containing super thermites. J. Propuls. Technol. 2013, 34, 129-134.

5. Dilip, S.; Vigor, Y.; Richard, A.Y. Metal-based nanoenergetic materials: Synthesis, properties, and applications. Prog. Energy Combust. Sci. 2017, 61, 293-365. 
6. Zhang, X.-T.; Song, W.-L.; Guo, L.-G.; Hu, M.-L.; Xie, C.-S. Preparation of carbon-coated Al nanopowders by laser-induction complex heating method. J. Propuls. Technol. 2007, 28, 333-338.

7. Zhou, J.; Ding, L.; An, J.; Zhu, Y.; Liang, Y. Study on the thermal behaviors of nano-Al based fuel air explosive. J. Therm. Anal. Calorim. 2017, 130,1111-1116. [CrossRef]

8. $\quad$ de Luca, L.T.; Galfetti, L.; Severini, F.; Meda, L.; Marra, G.; Vorozhtsov, A.B.; Sedoi, V.S.; Babuk, V.A. Burning of nano-aluminized composite rocket propellants. Combust. Explos. Shock Waves 2005, 41, 680-692.

9. Paravan, C.; Verga, A.; Maggi, F.; Galfetti, L. Accelerated ageing of micron- and nano-sized aluminum powders: Metal content, composition and non-isothermal oxidation reactivity. Acta Astronaut. 2019, 158, 397-406. [CrossRef]

10. Bockmon, B.S.; Son, S.F.; Asay, B.W.; Busse, J.R.; Mang, J.T.; Peterson, P.D.; Pantoya, M.L. Combustion performance of metastable intermolecular composites (MIC). Cpia Publ. 2002, 712, 613-624.

11. Borgonovo, C.; Apelian, D. Manufacture of Aluminum nanocomposites: A critical review. Mater. Sci. Forum 2011, 678, 1-22. [CrossRef]

12. Simpson, R.L.; Tillotson, T.M.; Hrubesh, L.W.; Gash, A.E. Nanostructured energetic materials derived from sol-gel chemistry. J. Non Cryst. Solid 2001, 285, 338-345.

13. Guo, Q.-X.; Nie, F.-D.; Yang, G.-C.; Li, J.-S.; Chu, S.-J. Preparation of RDX/resorcinol-formaldehyde (RF) nano-composite energetic materials by sol-gel method. Chin. J. Energetic Mater. 2006, 14, $268-271$.

14. Zhou, C.; Li, G.-P.; Luo, Y.-J. Preparation of $\mathrm{Fe}_{2} \mathrm{O}_{3} / \mathrm{Al}$ nano composite by sol-gel method. Chin. J. Explos. Propellants 2010, 33, 1-4.

15. Jiang, X.-B.; Liang, Y.-Q.; Zhang, J.-L.; Chen, J.-S. Preparation of RDX/SiO 2 booster membrane by sol-gel method. Chin. J. Energetic Mater. 2009, 17, 689-694.

16. Gash, A.E.; Tillotson, T.M.; Sateher, J.H., Jr.; Poco, J.F.; Hrubesh, L.W.; Simpson, R.L. Use of epoxides in the sol-gel synthesis of porous $\mathrm{Fe}_{2} \mathrm{O}_{3}$ monliths from Fe (III) salts. Chem. Mater. 2001, 13, 999-1007. [CrossRef]

17. Ma, Z.-Y.; Li, F.-S.; Chen, A.-S.; Song, H.-C. Preparation and characterization of Al/ammonium perchlorate composite particles. J. Propuls. Technol. 2004, 25, 373-376.

18. Ma, Z.-Y.; Li, F.-S.; Chen, A.-S.; Bai, H.-P. Preparation and thermal decomposition behavior of $\mathrm{Fe}_{2} \mathrm{O}_{3}$ /ammonium perchlorate composite nanoparticles. Acta Chim. Sin. 2004, 62, 1252-1255.

19. Xu, G.-C.; Zhang, L.-D. Nano Composite Materials; Chemical Industry Press: Beijing, China, 2002.

20. Xie, Q.-D. Preparation of Carbide and Nanocomposites by High Energy Ball Milling; Zhejiang University: Zhejiang, China, 2003.

21. Shi, X.-F. Preparation and Properties of Micro-Spherical Energetic Nanocompoistes Prepared by Spray Drying; North University of China: Taiyuan, China, 2015.

22. Yusoff, M.S.M.; Paulus, W.; Muslim, M. Synthesis of nano-sized alpha alumina using solvothermal and hydrothermal methods: A comparative study. In Proceedings of the 2012 International Conference on Enabling Science and Nanotechnology (ESciNano), IEEE, Johor Bahru, Malaysia, 5-7 January 2012.

23. Chen, D.; Zhao, Y.; Zhu, H.; Zheng, M.; Chen, G. Microstructure and mechanism of in-situ $\mathrm{Al}_{2} \mathrm{O}_{3}(\mathrm{p}) / \mathrm{Al}$ nano-composites synthesized by sonochemistry melt reaction. Trans. Nonferrous Met. Soc. China 2012, 22, 36-41. [CrossRef]

24. Gedanken, A. Using sonochemistry for the fabrication of nanomaterials. Ultrason. Sonochem. 2004, 11, 47-55. [CrossRef]

25. Martin Joe, A.; Welch Larry, H. Composition and Method for Preparing Oxidizer Matrix Containing Dispersed Metal Particles. WO Patent WO 2001/38264 Al, 27 August 2001.

26. Dossi, S.; Reina, A.; Maggi, F.; DeLuca, T.L. Innovative metal fuels for solid rocket propulsion. Int. J. Energ. Mater. Chem. Propul. 2012,11, 299-322.

27. Sullivan, K.T.; Chiou, W.; Fiore, R.; Zachariah, M.R. In situ microscopy of rapidly heated nano-Al and nano-Al/ $/ \mathrm{WO}_{3}$ thermites. Appl. Phys. Lett. 2010, 97, 133104.

28. Jian, G.; Piekiel, N.W.; Zachariah, M.R. Time-resolved mass spectrometry of nano-Al and nano-Al/CuO thermite under rapid heating: A mechanistic study. J. Phys. Chem. C 2012, 116, 26881-26887. [CrossRef]

29. Wang, H.; Zachariah, M.R.; Xie, L.; Rao, G. Ignition and combustion characterization of nano-Al-AP and nano-Al-CuO-AP micro-sized composites produced by electrospray technique. Energy Procedia 2015, 66, 109-112. [CrossRef]

30. Liu, P.; Liu, J.; Wang, M. Ignition and combustion of nano-sized aluminum particles: A reactive molecular dynamics study. Combust. Flame 2019, 201, 276-289. 
31. Chao, Z.; Guo-Ping, L.; Yun-Jun, L. Preparation and characterization of porous $\mathrm{Fe}_{2} \mathrm{O}_{3} / \mathrm{Al}$ composite energetic material. Chin. J. Explos. Propellants 2010, 33, 1-4.

32. Tillotson, T.M.; Gash, A.E.; Simpson, R.I.; Hrubesh, L.W.; Satcher, J.J.H.; Poco, J.F. Nanostructured energetic materials using sol-gel methodologies. J. Non Cryst. Solids 2001, 85, 338-345.

33. Jin, M.-M.; Luo, Y.-J. Preparation and characterization of NC/Al nano-composite energetic materials. Chin. J. Energetic Mater. 2013, 21, 230-234.

34. Zhu, Y.; Ma, X.-X.; Zhang, K.-L. Study on Nano-structured $\mathrm{MnO}_{2} / \mathrm{Al}$ Energetic Composite. Initiators Pyrotech. 2018, 1, 23-27.

35. Ke, X.; Zhou, X.; Gao, H.; Hao, G.Z.; Xiao, L.; Chen, T.; Liu, J.; Jiang, W. Surface functionalized core/shell structured $\mathrm{CuO} / \mathrm{Al}$ nanothermite with long-term storage stability and steady combustion performance. Mater. Des. 2018, 140, 179-187. [CrossRef]

36. Dreizin, E.L.; Schoenitz, M. Nano-composite energetic powders prepared by arrested reactive milling. Thermochim. Acta 2016, 636, 48-56.

37. Williams, R.A.; Schoenitz, M.; Dreizin, E.L. Validation of the thermal oxidation model for $\mathrm{Al} / \mathrm{CuO}$ nanocomposite powder. Combust. Sci. Technol. 2014, 186, 46-67. [CrossRef]

38. Wang, J.; Zheng, B.; Qiao, Z.-J.; Chen, J.; Zhang, L.-Y.; Zhang, L.; Li, Z.-Q.; Zhang, X.-Q.; Yang, G.-C. Construct 3D porous hollow $\mathrm{Co}_{3} \mathrm{O}_{4}$ micro-sphere: A potential oxidizer of nano-energetic materials with superior reactivity. Appl. Surf. Sci. 2018, 442, 767-772. [CrossRef]

39. Zakiyyan, N.; Wang, A.-Q.; Thiruvengadathan, R.; Staley, C.; Mathai, J.; Gangopadhyay, K.; Maschmann, M.R.; Gangopadhyay, S. Combustion of aluminum nanoparticles and exfoliated 2D molybdenum trioxide composites. Combust. Flame 2018, 187, 1-10. [CrossRef]

40. Dixon, G.P.; Martin, J.A.; Thompson, D. Lead-Free Precussion Peimer Mixes Based on Metastable Interstitial Composite (MIC) Technology. Patent US 5717159, 10 February 1998.

41. Troy, J.; Barbee, W.; Simpson, R.L.; Gash, A.E.; Joe, S.H., Jr. Nano-Laminate-Based Ignitors. Patent US 2004 0060625, 4 January 2004.

42. Williams, R.A.; Schoenitz, M.; Ermoline, A.; Dreizin, E.L. Low-temperature exothermic reactions in fully-dense $\mathrm{Al} / \mathrm{MoO}_{3}$ nanocomposite powders. Thermochim. Acta 2014, 594, 1-10. [CrossRef]

43. Wang, J.; Zhang, W.-C.; Shen, R.-Q.; Ye, J.-H.; Wang, X.-W. Research progress of nano thermite. Chin. J. Explos. Propellants 2014, 37, 1-9.

44. Jin, X.-Y.; Hu, Y.; Shen, R.-Q.; Ye, Y.-H. Preparation and laser ignition studies of Al/Ni energetic nanocomposite. Explos. Mater. 2012, 41, 12-15.

45. Nemtseva, S.Y.; Lebedev, E.A.; Shaman, Y.P.; Lazarenko, P.I.; Ryazanov, R.M.; Gavrilov, S.A.; Gromov, D.G. Nano-sized Al-Ni energetic powder material for heat release element of thermoelectric device. J. Phys. Conf. Ser. 2018, 1124. [CrossRef]

46. Lee, H.M.; Yun, J. Preparation of aluminum-oleic acid nano-composite for application to electrode for Si solar cells. Mater. Trans. 2011, 52, 1222-1227. [CrossRef]

47. Liu, X.; Li, Y.; Liu, Y.; Sun, D.; Guo, W.; Sun, X.; Feng, Y.; Chi, H.; Li, X.; Tian, F.; et al. Performance and microstructure characteristics in polyimide/nano-aluminum composites. Surf. Coat. Technol. 2017, 320, 103-108. [CrossRef]

48. Shen, L.-H.; Li, G.-P.; Luo, Y.-J.; Gao, K.; Chai, C.-P.; Ge, Z. Preparation of Al/B/ $/ \mathrm{Fe}_{2} \mathrm{O}_{3}$ nano-composite energetic materials by high energy ball milling. J. Solid Rocket Technol. 2014, 37, 233-237.

49. Yang, F.; Kang, X.-L.; Luo, J.-S.; Yi, Z.; Tang, Y.-J. Preparation of core-shell structure KClO4@Al/CuO nano energetic material and enhancement of thermal behavior. Sci. Rep. 2017, 7, 3730. [CrossRef] [PubMed]

50. Yang, Y.; Pan, Z.-H.; Li, L.-X.; Li, Y.-B.; Cao, X.-F. Preparation of nanometer NiB/Al composite and its thermal catalysis effect on AP decomposition. Chin. J. Energetic Mater. 2009, 17, 446-450.

51. Wang, R.-H.; Zhang, J.-L.; Wang, J.-Y.; Pan, J.; Zhang, J. Preparation and characterization of nano-composite energetic materials $\mathrm{Fe}_{2} \mathrm{O}_{3} / \mathrm{Al} / \mathrm{RDX}$. Chin. J. Energetic Mater. 2011, 19, 739-742.

52. Wang, R.-H.; Jin, R.-Y.; Wang, J.-Y.; Zhang, J.-L.; Wang, D.-J. Preparation of RDX/B/ $/ \mathrm{Fe}_{2} \mathrm{O}_{3}$ nano-composite energetic material with gel-template method. Chin. J. Energetic Mater. 2015, 23, 410-414.

53. Zhang, D.-D.; Huang, Y.-S.; Li, R.; Li, M.; Wang, J.-J.; Ge, M.-Z.; Zhang, H.-J.; He, Y.-L. Preparation and properties of $\mathrm{RDX} / \mathrm{Al} / \mathrm{SiO}_{2}$ nano-composite energetic materials. Chin. J. Energetic Mater. 2017, 25, 656-660.

54. Zhang, D.-D. Preparation and Properties of RDX Based Nanocomposite Energetic Materials; Nanjing University of Science and Technology: Nanjing, China, 2018. 
55. Pan, J.-J.; Zhang, J.-L.; Shang, F.-F.; Song, X.-X. Preparation and characterization of submicron composite energetic materials $\mathrm{RDX} / \mathrm{AP} / \mathrm{Al} / \mathrm{SiO}_{2}$. Shanxi Chem. Ind. 2011, 31, 15-17.

56. Pang, W.-Q.; De Luca, T.L.; Fan, X.-Z.; Wang, K.; Li, J.-Q.; Zhao, F.-Q. Progress on modification of high active aluminum powder and combustion agglomeration in chemical propellants. J. Solid Rocket Technol. 2019, 42, 42-53.

57. Carole, R. Al-Based Energetic nano Materials: Design, Manufacturing, Properties and Applications; Wiley: Hoboken, NJ, USA, 2015.

58. Puszynski, J.A. Processing and characterization of aluminum-based nanothermites. J. Therm. Anal. Calorim. 2009, 96, 677-685. [CrossRef]

59. Puszynski, J.A. Reactivity of Nano-Sized Aluminum with Metal Oxides and Water Vapor. Materials Research Society Proceedings; Materials Research Society: Boston, MA, USA, 2003.

60. Monk, I.; Schoenitz, M.; Jacob, R.J.; Dreizin, E.L.; Zachariah, M.R. Combustion characteristics of stoichiometric $\mathrm{Al}-\mathrm{CuO}$ nanocomposite thermites prepared by different methods. Combust. Sci. Technol. 2017, 189, 555-574. [CrossRef]

61. Demitrios, S.; Xianjin, J.; Ervin, B.; Edward, L.D. Aluminum burn rate modifiers based on reactive nanocomposite powders. Propellants Explos. Pyrotech. 2009, 35, 260-267.

62. Young, G.; Wang, H.; Zachariah, M.R. Application of nano-aluminum/nitrocellulose mesoparticles in composite solid rocket propellants. Propellants Explos. Pyrotech. 2015, 43, 413-418. [CrossRef]

63. Yan, Q.-L.; Zhang, X.-H.; Qi, X.-F.; Liu, M.; Li, X.-J. Preparation and application of nano-sized composite energetic materials. New Chem. Mater. 2011, 39, 36-39.

64. Zhang, M.; Wang, Y.; Song, X.-L.; Luo, T.-T. Preparation and characterization of NC/PETN nanocomposite. J. Ordnance Equip. Eng. 2018, 39, 182-186.

65. Weismiller, M.R.; Malchi, J.Y.; Lee, J.G.; Yetter, R.A.; Foley, T.J. Effects of fuel and oxidizer particle dimensions on the propagation of aluminum containing thermites. Proc. Combust. Inst. 2011, 33, 1989-1996. [CrossRef]

66. Rossi, C. Nano-energetic materials for MEMS: A review. J. Micro Electro Mech. Syst. 2007, 16, 919-931. [CrossRef]

67. Pang, W.-Q.; De Luca, L.T.; Gromov, A.; Cumming, A.S. Innovative Energetic Materials: Properties, Combustion Performance and Application; Springer: Taramani, India, 2020.

(C) 2020 by the authors. Licensee MDPI, Basel, Switzerland. This article is an open access article distributed under the terms and conditions of the Creative Commons Attribution (CC BY) license (http://creativecommons.org/licenses/by/4.0/). 